\title{
Asymmetric Capital-Tax Competition, Unemployment and Losses from Capital Market Integration
}

\author{
Rüdiger Pethig \\ Frieder Kolleß
}

CESIFO WORKING PAPER NO. 2795

CATEgOry 1: PubliC FinANCE

SEPTEMBER 2009

An electronic version of the paper may be downloaded

- from the SSRN website:

- from the RePEc website:

- from the CESifo website:

www.SSRN.com

www.RePEc.org

www.CESifo-group.org/wp 


\title{
Asymmetric Capital-Tax Competition, Unemployment and Losses from Capital Market Integration
}

\begin{abstract}
In a multi-country general equilibrium economy with mobile capital and rigid-wage unemployment, countries may differ in capital endowments, production technologies and rigid wages. Governments tax capital at the source to maximize national welfare. They account for tax base responses to their tax and take as given the world-market interest rate. We specify conditions under which - in contrast to free trade with undistorted labor markets welfare declines and unemployment increases in some countries (i) when moving from autarky to trade without taxation and/or (ii) when moving from trade without taxation to tax competition.
\end{abstract}

JEL Code: E24, H25, H87, J64, R13, F21.

Keywords: capital taxation, asymmetric tax competition, rigid wages, unemployment, losses from trade.

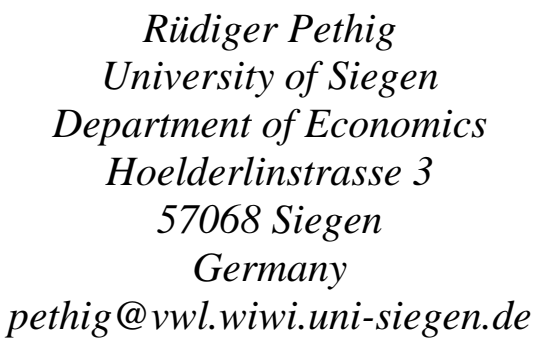

Rüdiger Pethig

partment of Economics

57068 Siegen

Germany

pethig@vwl.wiwi.uni-siegen.de 


\section{Asymmetric capital-tax competition, unemployment and losses from capital market integration}

\section{The problem}

The international mobility of capital has massively increased over the last decades, governments distort trade by taxing or subsidizing capital, and unemployment is a persistent phenomenon in many countries. The free-trade paradigm promises gains from international trade in a perfectly competitive world in the absence of taxation but leaves unanswered the question what the allocative impact is of trade when capital is mobile, when countries suffer from unemployment, and when their governments engage in capital-tax competition.

The present paper aims at exploring the impact of capital market integration in a multicountry economy with heterogeneous countries, persistent rigid-wage unemployment and capital-tax competition. Each country produces the same consumption good with the help of labor and capital, and unemployment results from excessively high and rigid wage rates. Countries may differ with respect to their rigid wage rates, capital endowments and production technologies. ${ }^{1}$ Governments levy capital taxes at the source whose rates are not sign constrained and whose revenues are recycled to the consumers. Governments choose their tax to maximize national income (= welfare) taking account of how the domestic firms' demands for capital respond to the tax. We use that model to investigate the changes in the countries' allocation and welfare, when moving from autarky to trade without taxation and from trade without taxation to tax competition.

There is a large and growing literature on capital tax competition. The classic papers of Zodrow and Mieszkowski (1986) and Wilson (1986) analyze the impact of capital-tax competition on the provision of public goods when labor markets are perfectly competitive. Some of the subsequent literature took up the issue of tax competition in the presence of labor market distortions, e.g. Fuest and Huber (1999), Leite-Monteiro et al. (2003), Eggert and Goerke (2004), Ogawa et al. (2006) and Aronsson and Wehke (2008). However, these studies assume identical countries and therefore yield limited insight only in allocative effects of the transition from autarky to trade and tax competition. Symmetric tax competition means that trade does not take place and that inefficiencies of tax competition, if any, hit all countries alike.

\footnotetext{
${ }^{1}$ The size of the countries' populations (= labor endowment) may vary as well. However, since all countries are assumed to suffer from unemployment the population size is irrelevant.
} 
Asymmetric tax competition is studied, e.g., by Wilson (1991), Bucovetsky (1991), DePater and Myers (1994), Peralta and van Ypersele (2005) and Sato and Thisse (2007). But none of these contributions deals with labor market distortions and unemployment ${ }^{2}$. Peralta and van Ypersele (2005) address the issue of 'gains from trade' and find for quadratic production functions that "... fiscal competition erodes some, but not all, of the gains from liberalization." (ibidem, p. 259). As we will present cases of trade losses in the present paper, Peralta and van Ypersele's result suggests that it is the combination of asymmetric tax competition and labor market distortions that has the potential of rendering capital market integration unfavorable for some countries.

Taking the time-honored free-trade paradigm as a reference, there is, of course, a large literature on trade under various conditions of second best. In the present context the contributions of Kemp and Negishi (1970) and Eaton and Panagariya (1979) are worth mentioning who focus on gains from trade when commodities are taxed and factor markets are distorted. However, they do not model capital-tax competition. More recently, the issue of gains from trade has been linked to capital-tax competition, e.g. by Kessler et al. (2003) and Lockwood and Makris (2006), who analyze capital-tax financed redistribution policies and voting in economies without labor market distortions. Aloi et al. (2009) present a model of two countries which are identical except that the labor market in one country is perfectly competitive and unionized in the other country. They determine conditions under which either country prefers autarky to capital market integration. In their model, no tax competition takes place.

Summing up, to our knowledge the consequences of capital market integration in a multicountry economy with labor market distortions and asymmetric capital-tax competition have not yet been analyzed in the literature. The present paper aims to fill that gap. It considers 'small countries' as in Zodrow and Mieszkowski (1986) and Wilson (1986) rather than modeling governments playing Nash in tax rates. With the concept of rigid-wage unemployment our model relates most closely to Ogawa et al. (2006). We deviate from their approach by dropping the issue of public-good provision ${ }^{3}$, by considering heterogeneous countries and by addressing the consequences of moving from autarky to trade and capital-tax competition. Fuest and Huber (1999) and later Ogawa et al. (2006) show that a government's optimal capital tax

\footnotetext{
${ }^{2}$ A limiting case is Sato and Thisse (2007) who consider a labor market with heterogeneous skills, costly training and the need of matching the firms' skill needs. Yet their analysis relates to full employment except for a hint in the concluding remarks that fiscal competition might well trigger unemployment in a country.

${ }^{3}$ The issue of optimal provision of public goods is dropped in many contributions to the tax competition literature such as Leite-Monteiro et al. (2003), Eggert and Goerke (2004), Peralta and van Ypersele (2005) and Sato and Thisse (2007). Suppressing the fiscal purpose of capital taxation allows isolating the welfare-maximizing government's incentive to stimulate or discourage the use of capital in production.
} 
rate may be positive or negative depending on whether capital and labor are substitutes or complements in production ${ }^{4}$. These properties of the production technology will turn out to have a major impact on the allocative consequences of capital market integration. That is why we will analyze technologies with capital and labor being either substitutes or complements. Ultimately, it is an empirical issue, of course, what the relevant production technology is like. However, as the pertaining empirical evidence is quite complex, if not ambiguous, e.g. Griliches (1969), Bergström and Panas (1992) and Duffy et al. (2004), it appears to be appropriate and necessary clarifying the analytical consequences of alternative assumptions on production technologies.

The paper is organized as follows. After having introduced the model in Section 2, we identify conditions in Section 3 under which countries gain or lose in the transition from autarky to trade if capital is internationally mobile and governments do not tax capital. In Section 4 we first characterize an individual government's optimal capital tax policy and show that it increases domestic employment for some given world market rate of interest. Then we investigate the allocative displacement effects that occur when the economy moves from trade without capital taxation to capital-tax competition. Under certain conditions that transition turns out to be welfare decreasing for some countries. Section 5 combines the results from the two previous sections and identifies conditions under which some countries suffer a welfare loss and a rise in unemployment in the transition from autarky to tax competition. Section 7 concludes. Formal proofs of all propositions are delegated to the Appendix.

\section{The model: rigid wages, mobile capital and capital taxation}

Consider an $n$-country economy in which each country $i=1, \ldots, n$ produces the amount

$$
y_{i}=Y^{i}\left(k_{i}, \ell_{i}\right)
$$

of a consumption good by means of capital input $k_{i}$ and labor input $\ell_{i}$ according to the strictly concave $e^{5}$ production function $Y^{i}$ that exhibits positive first derivatives. The consumption good and capital are traded on competitive world markets at price $p_{y} \equiv 1$ and interest rate

\footnotetext{
${ }^{4}$ If the output $Y(k, \ell)$ is produced with capital input $k$ and labor input $\ell$, capital and labor are said to be substitutes in production, if $Y_{k \ell}<0$, and complements, if $Y_{k \ell}>0$.

${ }^{5}$ Assuming strictly concave production functions is indispensible because otherwise we would not obtain welldefined factor demand functions. See equation (2) below. Unfortunately, in their general form strictly concave production functions give limited insights only. Therefore, we will later consider more specific parametric functional forms as well.
} 
$r$, respectively. Immobile labor is traded on domestic markets at the wage rate $w_{i}, i=1, \ldots, n$. The governments of all countries tax capital at the source such that the 'aggregate' producer in country $i$ faces the after-tax rental rate of capital, $\rho_{i}:=r+t_{i}$, where $t_{i}$ is the signunconstrained $^{6}$ capital tax rate. Firm $i$ maximizes profits $\pi_{i}:=y_{i}-w_{i} \ell_{i}-\rho_{i} k_{i}$ as a price taker giving rise to the standard factor demand functions

$$
k_{i}=K^{i}\left(\rho_{i}, w_{i}\right) \quad \text { and } \quad \ell_{i}=L^{i}\left(\rho_{i}, w_{i}\right),
$$

where $^{7} K_{\rho}^{i}=Y_{\ell \ell}^{i} / D<0, K_{w}^{i}=-Y_{k \ell}^{i} / D, L_{w}^{i}=Y_{k k}^{i} / D<0, L_{\rho}^{i}=-Y_{k \ell}^{i} / D$, and $D:=Y_{k k}^{i} Y_{\ell \ell}^{i}-$ $-\left(Y_{k \ell}^{i}\right)^{2}>0 ; Y_{k \ell}^{i}$ may be positive or negative.

Except for brief references to the benchmark model with flexible wage rates we focus exclusively on scenarios of persistent rigid wages that are sufficiently high as to make all countries suffer from unemployment. More formally, denote by $m_{i}$ the number of consumers residing in country $i$, let each consumer offer one unit of labor and consider situations of excess supply of labor, ${ }^{8}$

$$
m_{i}>L^{i}\left(\rho_{i}, w_{i}\right) \quad \text { for all } i=1, \ldots, n
$$

According to (3), $m_{i}-L^{i}\left(\rho_{i}, w_{i}\right)>0$ consumers are unemployed and the $L^{i}\left(\rho_{i}, w_{i}\right)$ jobs offered by firm $i$ are randomly allocated to consumers. As consumers spend their income on a single consumption good only we can do without utility functions.

The national income of country $i$ is $x_{i}:=r \bar{k}_{i}+\pi_{i}+t_{i} k_{i}+w_{i} \ell_{i}$, where $\bar{k}_{i}$ is country i's aggregate capital endowment and where profits $\pi_{i}$ and the tax revenues $t_{i} k_{i}$ are recycled to the consumers $^{9}$. Combining (1), (2) and $\pi_{i}=y_{i}-w_{i} \ell_{i}-\rho_{i} k_{i}$ yields national income (= welfare) $x_{i}$ as a function of $r, t_{i}$ and $w_{i}$ :

$$
X^{i}\left(t_{i}, r, w_{i}\right):=Y^{i}\left[K^{i}\left(r+t_{i}, w_{i}\right), L^{i}\left(r+t_{i}, w_{i}\right)\right]-r\left[K^{i}\left(r+t_{i}, w_{i}\right)-\bar{k}_{i}\right]
$$

\footnotetext{
${ }^{6}$ If $t_{i}<0$, capital is subsidized. To avoid clumsy wording we will use the term tax irrespective of the sign of $t_{i}$.

${ }^{7}$ Capital letters denote functions and subscripts to capital letters denote first derivatives. To simplify notation we write $Y_{k \ell}^{i}$ instead of $Y_{k_{i} \ell_{i}}^{i}$ etc.

${ }^{8}$ More precisely, (3) is assumed to hold in all equilibria to be specified below.

${ }^{9}$ We need not specify the shares of profits and tax revenues allocated to individual consumers because we refrain from focusing on utility distributions.
} 
The government of country $i=1, \ldots, n$ is supposed to maximize national income $X^{i}\left(t_{i}, r, w_{i}\right)$ with respect to the capital tax rate $t_{i}$. As the definition of $X^{i}\left(t_{i}, r, w_{i}\right)$ in (4) shows, it accounts for the impact of tax variations on its firm's factor demands (2) but takes as given the world price, $r$, of capital.

For predetermined tax rates $t_{1}, \ldots, t_{n}$ the condition for clearing the world capital market is

$$
\sum_{j} \bar{k}_{j}=\sum_{j} K^{j}\left(r+t_{j}, w_{j}\right)
$$

If (5) is satisfied, the world market for the consumption good is also cleared which follows from summing (4) over all $i$. The concept of general equilibrium for the $n$-country economy is straightforward: For given capital endowments $\bar{k}_{1}, \ldots, \bar{k}_{n}$ and for persistent rigid wage rates $w_{1}, \ldots, w_{n}$ a tax-competition equilibrium with unemployment is formally determined by the set $E:=\left\{t_{1}, \ldots, t_{n}, r,\left(x_{i}, y_{i}, k_{i}, \ell_{i}\right)_{i=1, \ldots, n}\right\}$ where the allocation $\left(x_{i}, y_{i}, k_{i}, \ell_{i}\right)_{i=1, \ldots, n}$ and the interest rate $r$ satisfy the equations (1) - (5) for $\left(t_{1}, \ldots, t_{n}\right)$, and where government $i=1, \ldots, n$ chooses its tax rate $t_{i}$ as to maximize (4).

It will turn out to be useful to consider also equilibria $E:=\left\{t_{1}, \ldots, t_{n}, r,\left(x_{i}, y_{i}, k_{i}, \ell_{i}\right)_{i=1, \ldots, n}\right\}$ in which tax rates are exogenously fixed rather than optimally chosen by the governments. We will call such equilibria constant-tax trade equilibria in contrast to tax-competition equilibria as defined in the last paragraph. Note that the no-tax trade equilibrium $\left(t_{1}=\ldots=t_{n} \equiv 0\right)$ is a special constant-tax trade equilibrium. When we later investigate the incidence of tax competition, we will exploit an equivalence between tax-competition equilibria and constant-tax trade equilibria which arises because due to (5) the capital market equilibrium depends on $r$ and $t_{1}, \ldots, t_{n}$ through $\rho_{1}, \ldots, \rho_{n}$ only. In formal terms, we state that equivalence in

Proposition 1 (Neutrality of uniform variations in tax rates).

If $E_{\tau}:=\left\{t_{1 \tau}, \ldots, t_{n \tau}, r_{\tau},\left(x_{i \tau}, y_{i \tau}, k_{i \tau}, \ell_{i \tau}\right)_{i=1, \ldots, n}\right\}$ is a tax-competition equilibrium or a constant-tax trade equilibrium, $E_{\theta}:=\left\{t_{1 \tau}+\theta, \ldots, t_{n \tau}+\theta, r_{\tau}-\theta,\left(x_{i \tau}, y_{i \tau}, k_{i \tau}, \ell_{i \tau}\right)_{i=1, \ldots, n}\right\}$ is a constant-tax trade equilibrium for all $\theta<r$. 
Proposition 1 is a standard result in tax incidence theory. Uniform variations in capital tax rates are non-distortionary because the total supply of capital $\left(=\sum_{j} \bar{k}_{j}\right)$ is perfectly price inelastic. Thus uniform changes in all tax rates can be exactly offset by changes in the interest rate of equal size and opposite sign. Proposition 1 will be used in the proof of our main result in Section 4.2 below.

\section{From autarky to trade without taxation}

Our first step toward investigating gains or losses from tax competition is to explore the allocative changes that occur when the countries move from autarky to trade in the absence of capital taxation. For the model introduced in the previous section, the reference scenario of autarky is straightforward. All capital markets are national and (5) is replaced by $\bar{k}_{i}=K^{i}\left(r_{i}+t_{i}, w_{i}\right)$ for $i=1, \ldots, n$ with $r_{i}$ denoting the interest rate in country $i$. Note first that in autarky capital taxation is non-distortionary because the supply of capital is perfectly inelastic in each country. Hence we set $t_{i} \equiv 0$, for convenience. Since we allow countries to differ in their fundamentals 'capital endowments', 'production technologies' and 'wage rates', the equilibrium interest rate in autarky will generally differ across countries. Using the general functional form (1) of the production function it is hard to specify properties of the mapping from the fundamentals to the autarkic equilibrium interest rate. We therefore resort to CES production functions in

Proposition 2 (Determinants of the size of the equilibrium interest rate in autarky)

Suppose capital is untaxed and country i's production function is CES, i.e. it satisfies

$$
Y^{i}\left(k_{i}, \ell_{i}\right)=a_{o i}\left(a_{k i} k_{i}^{-e_{i}}+a_{\ell i} \ell_{i}^{-e_{i}}\right)^{-\frac{b_{i}}{e_{i}}},
$$

where $\left.a_{o i}>0, a_{k i}>0, a_{\ell i}>0, \sigma_{i}>0, \sigma_{i} \neq 1, b_{i} \in\right] 0,1\left[\right.$, and $e_{i}:=\left(1-\sigma_{i}\right) / \sigma_{i}$.

For any given elasticity of substitution, $\sigma_{i}>0, \sigma_{i} \neq 1$, country i's autarkic equilibrium interest rate, $r_{i a}$, is decreasing in its capital endowment, $\bar{k}_{i}$.

Following an increase in the rigid wage rate, $r_{i a}$ rises / remains unchanged / declines depending on whether $\sigma_{i}$ is greater than / equal to / smaller than $c_{i}=1 /\left(1-b_{i}\right)>1$. 
Clearly, expanding the capital endowment increases capital abundance and hence reduces the price for capital ( $r_{i a} \downarrow$ ). Increasing the wage rate makes capital scarcer $\left(r_{i a} \uparrow\right)$ or less scarce ( $\left.r_{i a} \downarrow\right)$ depending on whether capital and labor are substitutes $\left(\sigma_{i}>c_{i}\right)$ or complements $\left(\sigma_{i}<c_{i}\right)$. Proposition 2 can be conveniently used to compare the autarkic equilibrium interest rate of different countries whose production functions are CES. To see that suppose some countries $i$ and $j$ are characterized by the parameters $\left(\bar{k}_{i}, w_{i}\right)$ and $\left(\bar{k}_{j}, w_{j}\right)$ and observe that implicitly Proposition 2 defines a function, say $R^{h}$, such that $r_{h a}=R^{h}\left(\bar{k}_{h}, w_{h}\right)$ for $h=i, j$. If both countries use the same production function $\left(R^{i}=R^{j}=R\right)$, they have the same autarkic interest rate $\left(r_{i a}=r_{j a}\right)$, if and only if $R\left(\bar{k}_{i}, w_{i}\right)=R\left(\bar{k}_{j}, w_{j}\right)$. Moreover, the inequality $r_{i a}>r_{j a}$ holds, if, ceteris paribus, either $\left\{\bar{k}_{i}<\bar{k}_{j}\right\}$ or $\left\{w_{i}>w_{j}\right.$ and $\left.\sigma>c\right\}$ or $\left\{w_{i}<w_{j}\right.$ and $\left.\sigma<c\right\}$.

Suppose now that all countries have attained their autarkic equilibrium and the borders are subsequently opened for trade in capital and the consumption good while all governments refrain from taxation. It is straightforward from (5) (with $t_{i} \equiv 0$ for all $i$ ) that the no-tax trade equilibrium interest rate, denoted $r_{o}$, satisfies $\left.r_{o} \in\right] r_{a}^{\min }, r_{a}^{\max }\left[\right.$, when $r_{a}^{\min }$ is the smallest and $r_{a}^{\max }$ is the largest autarkic equilibrium interest rate of all countries and $r_{a}^{\min }<r_{a}^{\max }$. For any country $i$ with autarkic interest rate $r_{i a}$ the allocative consequences of the transition from autarky to the no-tax trade equilibrium clearly depend on the sign of the difference $r_{o}-r_{i a}$. We take this difference as our point of departure for analyzing the impact of moving from autarky to the no-tax trade equilibrium and explicitly allow for different production technologies. The results are summarized in

\section{Proposition 3 (Transition from autarky to no-tax trade)}

Suppose all governments refrain from taxation ( $t_{i} \equiv 0$ for all $i$ ) and consider the transition of the n-country economy from its autarky equilibrium (subscript a) to its zero-tax trade equilibrium (subscript o).

(i) The allocative impacts of that transition are summarized in Table 1.

(ii) Suppose the cases 1 or 7 in Table 1 apply and the production functions are CobbDouglas, defined by 
$Y^{i}\left(k_{i}, \ell_{i}\right)=k_{i}^{\alpha_{i}} \ell_{i}^{\beta_{i}}$ for all $i$ with $\alpha_{i}>0, \beta_{i}>0$ and $\alpha_{i}+\beta_{i}=: b_{i}<1$.

If the production functions are the same across countries $\left(\alpha_{i}=\alpha\right.$ and $\beta_{i}=\beta$, all $\left.i\right)$ then the following equivalences hold:

$\bar{k}_{i}\left\{\begin{array}{l}> \\ = \\ <\end{array}\right\} \omega_{i} \bar{k}_{\varnothing} \Leftrightarrow r_{o}\left\{\begin{array}{l}> \\ = \\ <\end{array}\right\} r_{i a} \Leftrightarrow \ell_{i o}\left\{\begin{array}{l}< \\ = \\ >\end{array}\right\} \ell_{i a} \Leftrightarrow x_{i o}\left\{\begin{array}{c}< \\ = \\ >\end{array}\right\} x_{i a}$,

where $\bar{k}_{\varnothing}:=\frac{\sum_{j} \bar{k}_{j}}{n}$ and $\omega_{i}:=\frac{n w_{i}^{-\beta c}}{\sum_{j} w_{j}^{-\beta c}}$.

(iii) If Case 6 in Table 1 applies and the production function is CES, (6), country i loses from trade if the elasticity of substitution in production, $\sigma_{i}$, satisfies

$$
\sigma_{i}>c_{i}+\frac{\left(k_{i o}-\bar{k}_{i}\right)\left(w_{i}+r_{o} q_{i o}\right)}{w_{i} k_{i o}}>c_{i} \text {, where } q_{i}:=\left(\frac{a_{k i}}{a_{\ell i}}\right)^{\sigma_{i}}\left(\frac{w_{i}}{r}\right)^{\sigma_{i}} \text { and } c_{i}:=\frac{1}{1-b_{i}}>1 \text {. }
$$

\begin{tabular}{|c|c|c|c|c|c|c|c|}
\cline { 2 - 8 } \multicolumn{1}{c|}{} & \multicolumn{3}{c|}{$r_{o}>r_{i a}$} & $r_{o}=r_{i a}$ & \multicolumn{3}{c|}{$r_{o}<r_{i a}$} \\
\hline \hline Case No. & $L_{r}^{i}<0$ & $L_{r}^{i}>0$ & $L_{r}^{i}=0$ & $L_{r}^{i} \gtreqless 0$ & $L_{r}^{i}=0$ & $L_{r}^{i}>0$ & $L_{r}^{i}<0$ \\
\hline \hline$\ell_{i o}-\ell_{i a}$ & - & + & 3 & 4 & 5 & 6 & 7 \\
\hline$k_{i o}-k_{i a}$ & - & - & - & 0 & + & + & + \\
\hline$y_{i o}-y_{i a}$ & - & $?$ & - & 0 & + & $?$ & + \\
\hline$x_{i o}-x_{i a}$ & $?(-)^{*)}$ & + & + & 0 & - & $?(-)^{*)}$ & + \\
\hline
\end{tabular}

*) For details see the Propositions 2ii and 2iii

Table 1: Allocative impacts of the transition from autarky to no-tax trade

A few remarks on Table 1 are in order. The top row distinguishes the cases in which country $i$ 's autarkic equilibrium interest rate, $r_{i a}$, is lower than, equal to or higher than the world market interest rate in the no-tax trade equilibrium, $r_{o}$. Note that one can combine that information with the results established in Proposition 2 to trace the difference $r_{o}-r_{i a}$ to differences in capital endowments and rigid wages ${ }^{10}$. The second row in Table 1 relates to properties of

\footnotetext{
${ }^{10}$ Recall that Proposition 2 allows identifying the capital endowments and the wage rates as determinants of the differences $r_{o}-r_{i a}$ for the case of identical CES production functions.
} 
the labor demand of country i's firm, which in turn are determined by properties of the production function as shown in equation (2). To be more specific, if production functions are Cobb-Douglas, (7), we have $Y_{k \ell}^{i}>0$. Hence for Cobb-Douglas the Cases 1, 4 and 7 apply. CES production functions (6) exhibit $Y_{k \ell}^{i} \lesseqgtr 0$, if and only if $\sigma_{i} \gtreqless c_{i}$. Therefore, such functions are examples for the Cases 2, 4 and 6, if $\sigma_{i}>c_{i}$, for the Cases 1, 4 and 7, if $\sigma_{i}<c_{i}$, and for the knife-edge Cases 3 and 5, if $\sigma_{i}=c_{i}$. Case 4 is trivial but not entirely uninteresting for some conclusions in the next section.
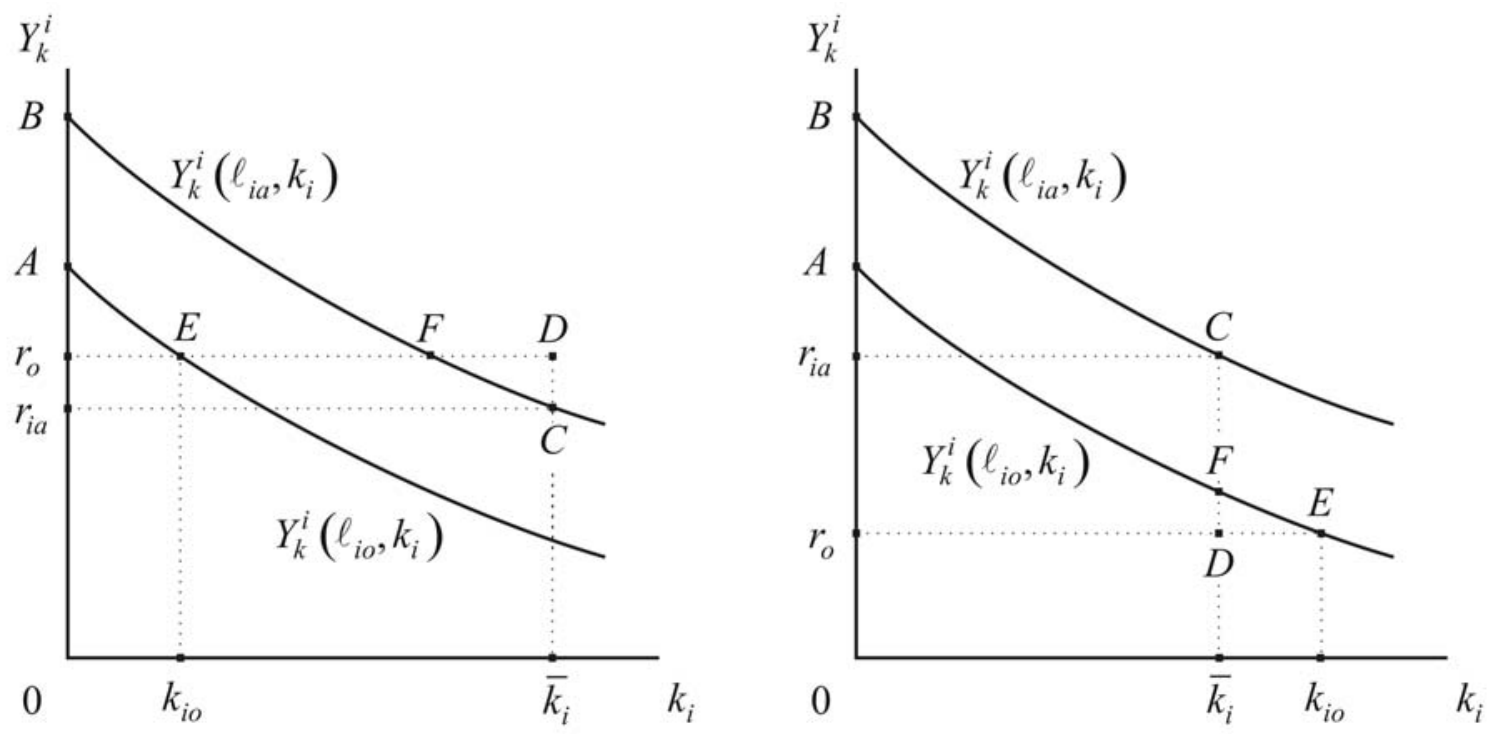

Figure 1: Illustration of the cases 1 and 6 in Table 1

The results listed in Table 1 can be easily illustrated. In Figure 1 we take up the Cases 1 and 6 of Table 1 that are unclear in the sign of $x_{i o}-x_{i a}$ and leave the illustration of the other cases to the reader. In both panels of Figure $1, y_{i a}$ is given by the area $0 B C \bar{k}_{i}$, and $y_{i o}$ is given by $0 A E k_{i o}$. In Case 1 capital is exported, and the value of these exports is equal to the area $\bar{k}_{i} D E k_{i o}$ in the left panel of Figure 1. In Case 6 capital is imported, and the value of these imports is equal to the area $\bar{k}_{i} D E k_{i o}$ in the right panel of Figure 1 . It follows that in Case 1 [Case 6] we have $x_{i o}=0 A E D \bar{k}_{i}$ such that $x_{i o}$ is smaller than / equal to / greater than $x_{i a}$, if and only if the area $A B F E[A B C F]$ is greater than / equal to / smaller than $D F C$ [DFE].

According to Table 1 country $i$ unambiguously gains from trade in the Cases 2, 3 and 7, while the welfare change in the Cases 1 and 6 remains unclear for general production functions. To gain additional insights in changes of national income in the unclear cases, we have specified 
the production technology in Proposition 3ii by Cobb-Douglas functions thus restricting the focus of Proposition 3ii to the Cases 1 or 7 of Table 1, as argued above.

The striking result of Proposition 3ii is that with Cobb-Douglas functions countries lose from trade - and suffer from higher unemployment - in Case 1 of Table 1 and they gain from trade - and enjoy higher employment - in Case 7 of Table $1 .{ }^{11}$ Proposition 3iii demonstrates that countries with CES production functions may also lose from trade if the elasticity of substitution is large enough.

As mentioned above, for CES production functions we can use Proposition 2 to specify conditions on fundamentals under which a country will export or import capital after the borders are opened. For Cobb-Douglas functions Proposition 3ii establishes an even more informative clear relationship between the difference in interest rates, $r_{i a}-r_{o}$, on the one hand and capital endowments and wages of all countries, on the other hand. It is therefore worthwhile analyzing and interpreting (8) in some more detail. Suppose first the countries differ in their capital endowments only. If the level of rigid wages is the same in all countries, we have $\omega_{i}=1$ for all $i$ such that (8) is turned into

$$
\bar{k}_{i}\left\{\begin{array}{l}
> \\
= \\
<
\end{array}\right\} \bar{k}_{\varnothing} \Leftrightarrow r_{o}\left\{\begin{array}{l}
> \\
= \\
<
\end{array}\right\} r_{i a} \Leftrightarrow x_{i o}\left\{\begin{array}{l}
< \\
= \\
>
\end{array}\right\} x_{i a} .
$$

Under these conditions country $i$ loses [gains] from trade, if and only if its capital endowment exceeds [falls short of] the countries' average capital endowment, $\bar{k}_{\varnothing}$. If capital is relatively abundant $\left(\bar{k}_{i}>\bar{k}_{\varnothing}\right)$, country i's equilibrium interest rate in autarky is low $\left(r_{i a}<r_{o}\right)$ and is bound to rise when capital is internationally traded. Recall that $K_{r}^{i}<0$ holds for all strictly concave production functions, and that $L_{r}^{i}<0$ holds because of (7). Therefore country $i$ will use less capital and labor and will consequently produce less output, so much less, that the (new) revenues from exporting capital do not compensate for the reduction in output. ${ }^{12}$ Conversely, countries with a relatively small capital endowment $\left(\bar{k}_{i}<\bar{k}_{\varnothing}\right)$ will face a lower interest rate in trade equilibrium ( $r_{i a}>r_{o}$ ) which, in turn, boosts the input of both capital and labor such that the extra value of output is greater than the expenditure on capital imports. This re-

\footnotetext{
${ }^{11}$ Case 7 applies for more general production functions as well.

${ }^{12}$ Note that if the wage rate were flexible, $w_{i}$ would shrink to restore the full employment equilibrium in the labor market which would then tend to boost domestic production.
} 
sult confirms the gains from trade stated already under more general conditions in the Case 7 of Table 1.

To focus on the role played by rigid wages, suppose all countries are endowed with the same amount of capital, $\bar{k}_{1}=\ldots=\bar{k}_{n}=\bar{k}_{\varnothing}$, but differ with respect to their wage rates. Invoking (8), we establish the following equivalences:

$$
1\left\{\begin{array}{l}
> \\
= \\
<
\end{array}\right\} \omega_{i} \Leftrightarrow w_{i}\left\{\begin{array}{l}
> \\
= \\
<
\end{array}\right\} \tilde{w} \Leftrightarrow r_{o}\left\{\begin{array}{l}
> \\
= \\
<
\end{array}\right\} r_{i a} \Leftrightarrow x_{i o}\left\{\begin{array}{l}
< \\
> \\
>
\end{array}\right\} x_{i a} \text {, where } \tilde{w}:=\left(\sum_{j} \frac{w_{j}^{-\beta c}}{n}\right)^{-\frac{1}{\beta c}} \text {. }
$$

Hence in that case, there is a positive number $\tilde{w}$, the same for all countries, such that country $i$ loses / is equally well off / gains from trade, if and only if its wage $w_{i}$ is above / equal to / below $\tilde{w}$. The magnitude of the threshold value $\tilde{w}$ is unclear. We would like to know, in particular, how $\tilde{w}$ relates to $w_{\varnothing}:=\sum_{j} w_{j} / n$, the average wage. One can show ${ }^{13}$ that

$$
\tilde{w}>w_{\varnothing} \text {, if and only if } n>\left[\left(\sum_{j} w_{j}\right)^{\beta c} / \sum_{j} w_{j}^{\beta c}\right]^{\frac{1}{1+\beta c}}>0 \text {. }
$$

In other words, in an economy with a sufficiently large number of countries only those countries lose from trade whose wage rate is well above the average wage rate. Note that the threshold value which needs to be exceeded for the number of countries to be large enough depends on the level of wage rates and on parameters of the Cobb-Douglas technology.

To highlight the consequences of rigid wages in the transition from autarky to trade from another perspective, we establish

\section{Proposition 4 (Transition from autarky to no-tax trade with flexible wages)}

Suppose that all governments refrain from taxation $\left(t_{i} \equiv 0\right.$ for all $\left.i\right)$, that wages are flexible, and that production functions are Cobb-Douglas, (7), the same across countries. The transition of the n-country economy from autarky (subscript a) to its no-tax trade equilibrium (subscript o) is characterized by

$$
\bar{k}_{i}\left\{\begin{array}{l}
> \\
= \\
<
\end{array}\right\} \bar{m}_{i} \bar{k}_{\varnothing} \Leftrightarrow r_{o}\left\{\begin{array}{l}
> \\
= \\
<
\end{array}\right\} r_{i a} \Leftrightarrow w_{i o}\left\{\begin{array}{l}
< \\
= \\
>
\end{array}\right\} w_{i a} \Leftrightarrow x_{i o}\left\{\begin{array}{l}
> \\
= \\
>
\end{array}\right\} x_{i a} \text {, where } \bar{m}_{i}=\frac{n m_{i}^{\beta \gamma}}{\sum_{j} m_{j}^{\beta \gamma}}
$$

\footnotetext{
${ }^{13}$ The proof is provided at the end of the Appendix.
} 
As expected, Proposition 4 confirms for the model at hand the general gains-from-trade result for economies with a full set of perfectly competitive markets. In the present context the purpose of Proposition 4 is to use (9) as a reference for further interpretation of the equivalences (8) from Proposition 3ii. To keep the exposition simple, we restrict that comparison to wage rates and labor endowments satisfying the condition $\bar{\omega}_{i}=\bar{m}_{i}=1$, which holds, e.g., if we set $w_{1}=w_{2}=\ldots=w_{n}$ in Proposition 3ii and $m_{1}=m_{2}=\ldots=m_{n}$ in Propositions 4. Obviously, in that case the first equivalences in (8) and (9) are the same. However, (9) shows that maintaining full employment of labor after opening the borders results in a lower wage rate in capitalrich countries and a higher wage rate in capital-poor countries. In the capital-rich country we find that $w_{i o}<w_{i a}<w_{i}$, where the wage rates $w_{i o}$ and $w_{i a}$, respectively, are equilibrium rates in autarky and trade in the flexible-wage scenario of Proposition 4, while $w_{i}$ is the rigid wage rate of Proposition 3ii. Hence when the wage rate is rigid, allowing for trade widens the difference between the rigid wage rate and the respective equilibrium wage rates in case of flexi-

ble wages $\left[\left(w_{i}-w_{i o}\right)>\left(w_{i}-w_{i a}\right)\right]$. As a consequence, the labor market disequilibrium is aggravated and unemployment rises, which in turn reduces national income (last equivalence in (8)). In contrast, for the capital-poor country we find the inequalities $w_{i a}<w_{i o}<w_{i}$ which imply that opening the borders for trade reduces the difference between the rigid wage rate and the respective equilibrium wage rates in case of flexible wages $\left[\left(w_{i}-w_{i o}\right)<\left(w_{i}-w_{i a}\right)\right]$. Therefore trade diminishes the labor market disequilibrium and thus raises employment as well as national income.

\section{$4 \quad$ From trade without taxation to capital tax competition}

Having clarified the allocative consequences of the transition from autarky to trade without taxation in the previous section we now take as our point of departure the trade equilibrium without taxation and analyze the allocative impact of tax competition. As a first step toward that end it is necessary and useful to take a closer look at the government's optimization calculus.

\subsection{Properties and implications of an individual government's optimal capital tax}

By assumption, governments choose their capital tax as to secure the maximum national income (= welfare), (4), for any given interest rate. The resultant optimal tax rates are character- 
ized in

Proposition 5 (Properties of the optimal capital tax).

Government i's optimal tax rate satisfies the condition ${ }^{14,15}$

$$
t_{i}=-\frac{w_{i} L_{\rho}^{i}}{K_{\rho}^{i}}=\frac{w_{i} Y_{\ell \mathrm{k}}^{i}}{Y_{\ell \ell}^{i}} .
$$

If the production functions are CES , (6), or Cobb-Douglas, (7), respectively, (10) is turned into

$$
t_{i}=\frac{\sigma_{i}-c_{i}}{\left(a_{k i} / a_{\ell i}\right)^{\sigma_{i}} c_{i} w_{i}^{\sigma_{i}-1} \rho_{i}^{-\sigma_{i}}+\sigma_{i} \rho_{i}^{-1}} \quad \text { and } \quad t_{i}=-\beta_{i} r<0
$$

where $a_{k i}>0, a_{\ell i}>0, \sigma_{i} \neq 1, c_{i}:=1 /\left(1-b_{i}\right)$ and $\rho_{i}:=r+t_{i}$.

Since $L_{r}^{i} \gtreqless 0 \Leftrightarrow Y_{k \ell}^{i} \lesseqgtr 0$, the optimal tax rate is negative if the production function is CobbDouglas. In case of CES production functions we have $Y_{k \ell}^{i} \lesseqgtr 0$, if and only if $\sigma_{i} \gtreqless c_{i}$, and therefore $t_{i} \lesseqgtr 0$ if and only if $\sigma_{i} \lesseqgtr c_{i}$. When production functions are Cobb-Douglas, the optimal tax rates are uniform across countries, if and only if the technology is the same in all countries. Interestingly, differences with respect to their capital endowments and wage rates do not translate into differences in optimal tax rates. When production functions are CES, the optimal tax rates are the same across countries, if and only if all countries have identical production functions and identical wage rates. Differences in capital endowments do not matter. Cases of uniform identical tax rates will be of some interest in Section 4.2 below.

By presupposition, if the government sets its tax rate according to (10), the country's income is maximized. But it is not clear how income maximization changes the level of employment, in particular, if we allow for different signs of $Y_{\ell k}^{i}$. We provide the answer in

Proposition 6 (Income maximization always promotes employment)

\footnotetext{
${ }^{14}$ Note that in (10) the terms $L_{\rho}^{i}$ and $K_{\rho}^{i}$ are functions of $t_{i}$.

15 The equation (10) has been derived by Fuest and Huber (1999) and later by Ogawa et al. (2006). Fuest and Huber (1999) employ a right-to-manage model of wage bargaining for the labor market. When they model governments maximizing utility for a given wage rate; they derive an optimal tax rate in their equation (26) equal to (10) for $e^{\prime}=0$. Ogawa et al. (2006) derive (10) in a setup where governments levy a head tax and a capital tax and finance a public good. Irrespective of these differences, the rationale of levying the capital tax in the present model is the same as in Fuest and Huber (1999) and Ogawa et al. (2006).
} 
Let $t_{i}^{*}$ be the optimal tax rate of government $i$ (satisfying (10)), if some interest rate $r_{o}$ prevails. Irrespective of the sign of $t_{i}^{*}\left(i . e\right.$. the sign of $\left.Y_{\ell k}^{i}\right)$ it is true that the government's optimal tax rate increases employment along with national income as compared to the no-tax strategy $\left[L^{i}\left(r_{o}+t_{i}^{*}, w_{i}\right)>L^{i}\left(r_{o}, w_{i}\right)\right]$.

To see the rationale of that synergism observe that the change in national income resulting from a small variation in the tax rate is given by

$$
X_{t}^{i}=Y_{k}^{i} K_{\rho}^{i}+Y_{l}^{i} L_{\rho}^{i}-r K_{\rho}^{i}=\left(\rho_{i}-r_{o}\right) K_{\rho}^{i}+w_{i} L_{\rho}^{i}=t_{i} K_{\rho}^{i}+w_{i} L_{\rho}^{i},
$$

if the wage rate is rigid. If the labor market were perfectly competitive, the term $Y_{\ell}^{i} L_{\rho}^{i}$ with $Y_{\ell}^{i}=w_{i}$ would be absent. As an immediate implication optimality would require to abstain from taxation ( $X_{t}^{i}=0 \Leftrightarrow t_{i}=0$ ). However, since the wage rate is rigid, the derivative of national income with respect to the tax rate is equal to the sum of the components $\left(\rho_{i}-r_{o}\right) K_{\rho}^{i}$ and $w_{i} L_{\rho}^{i}$. To interpret these terms suppose capital is taxed $\left(t_{i}=\rho_{i}-r_{o}>0\right)$ in the initial situation and the tax rate is increased, $d t_{i}=d \rho_{i}>0$. We then observe the partial marginal benefit effect $-r K_{\rho}^{i}>0$ of increased capital export revenues or reduced expenditures on capital imports, and $\rho_{i} K_{\rho}^{i}<0$ is the marginal cost of reduced output. Hence $\left(\rho_{i}-r_{o}\right) K_{\rho}^{i}<0$. The sign of $w_{i} L_{\rho}^{i}$ depends on whether $Y_{\ell k}^{i}>0$ or $Y_{\ell k}^{i}<0$. If $Y_{\ell k}^{i}>0$, the drop in capital input (following $d t_{i}=d \rho_{i}>0$ ) diminishes the marginal productivity of labor, $Y_{\ell}^{i}$, ceteris paribus. However, the first-order condition for profit maximization, $Y_{\ell}^{i}=w_{i}$, and the rigid wage rate $w_{i}$ induce the firm to 'restore' the former level of $Y_{\ell}^{i}$. It does so by reducing its labor input, $L_{\rho}^{i}<0$ such that $w_{i} L_{\rho}^{i}<0$ is another marginal cost term yielding $X_{t}^{i}=\left(\rho_{i}-r_{o}\right) K_{\rho}^{i}+w_{i} L_{\rho}^{i}<0$, if $t_{i}>0$. To attain the first-order condition for a maximum of $x_{i}$ it is therefore necessary to choose $\rho_{i}<r$ and hence a capital subsidy, $t_{i}<0$, in this scenario. Analogous arguments apply to the case $Y_{\ell k}^{i}<0$.

Recall the qualification of Proposition 6 that government $i$ 's promotion of employment is subject to the condition that it takes the interest rate as given. To fix our ideas take as the baseline the no-tax trade equilibrium with its equilibrium interest rate $r_{o}$ and suppose that all govern- 
ments introduce their optimal capital tax taking the interest rate $r_{o}$ as given. The clear implication of Proposition 6 is that all countries will raise their income as well as their level of employment. The bad news is, however, that the world capital market will not be in equilibrium anymore. Hence to restore equilibrium the world interest rate will have to change, in general, giving rise to the possibility that tax competition may partly offset or perhaps even defeat the government's effort to promote both welfare and employment. We will study that issue in the following subsection.

\subsection{The impact of tax competition as compared to trade without taxation}

Starting from the scenario of trade without taxation we wish to determine how tax competition changes the allocation attained in the no-tax trade equilibrium. In other words, we now take as a benchmark the no-tax trade equilibrium and compare the pertaining allocation with the allocation attained in tax-competition equilibrium. Analogous to the role of the difference $r_{i a}-r_{o}$ in case of the transition from autarky to trade (Proposition 3), the change in the interest rate from $r_{o}$ (no-tax trade equilibrium) to $r_{\tau}$ (tax-competition equilibrium) will now turn out to play an important role. It is therefore important to know what determines the sign of the difference $r_{\tau}-r_{o}$. A clear-cut answer is possible, if sign $t_{i \tau}$ is the same for all $i$. If $t_{i \tau}<0$ for all $i$, then $r_{\tau}>r_{o}$ because $\sum_{j} \bar{k}_{j}<\sum_{j} K^{j}\left(r_{o}+t_{j \tau}, w_{j}\right)$. In that case $r$ must rise to restore equilibrium on the capital market, (5). Likewise, if $t_{i \tau}>0$ for all $i$, then $r_{\tau}<r_{o}$ because $\sum_{j} \bar{k}_{j}>\sum_{j} K^{j}\left(r_{o}+t_{j \tau}, w_{j}\right)$. Now $r$ must decline to restore equilibrium on the capital market. If technologies are mixed such that $t_{i \tau}<0$ for some countries and $t_{i \tau}>0$ for others, the difference $r_{\tau}-r_{o}$ may take on either sign.

Keeping these preliminaries in mind we are now ready to compare the allocations of the notax trade equilibrium and the tax-competition equilibrium in

\section{Proposition 7 (Transition from trade without taxation to tax competition)}

Consider the no-tax trade equilibrium $E_{o}:=\left\{t_{1 o}=0, \ldots, t_{n o}=0, r_{o},\left(x_{i o}, y_{i o}, k_{i o}, \ell_{i o}\right)_{i=1, \ldots, n}\right\}$ and the associated tax-competition equilibrium $E_{\tau}:=\left\{t_{1 \tau}, \ldots, t_{n \tau}, r_{\tau},\left(x_{i \tau}, y_{i \tau}, k_{i \tau}, \ell_{i \tau}\right)_{i=1, \ldots, n}\right\}$, where $t_{i \tau}$ satisfies (10) for all $i$. The allocation $\left(x_{i \tau}, y_{i \tau}, k_{i \tau}, \ell_{i \tau}\right)_{i=1, \ldots, n}$ of the tax-competition equilibrium deviates from the no-tax trade allocation $\left(x_{i o}, y_{i o}, k_{i o}, \ell_{i o}\right)_{i=1, \ldots, n}$ as shown in Table 2. 


\begin{tabular}{|c|c|c||c||c|c|c|c|}
\hline $\begin{array}{c}\text { sign } \\
\left.r_{\tau}-r_{o}\right)\end{array}$ & $\operatorname{sign} L_{\rho}^{i}$ & $\operatorname{sign}\left(t_{i \tau}+\Delta r\right)$ & $N o$. & $\ell_{i \tau}-\ell_{i o}$ & $k_{i \tau}-k_{i o}$ & $y_{i \tau}-y_{i o}$ & $x_{i \tau}-x_{i o}$ \\
\hline$r_{\tau}>r_{o}$ & $L_{\rho}^{i}<0$ & $\left.t_{i \tau}+\Delta r<0 *\right)$ & 1 & + & + & + & + \\
& $L_{\rho}^{i}>0$ & $t_{i \tau}+\Delta r>0$ & 2 & - & - & - & - \\
\hline$r_{\tau} \neq r_{o}$ & $L_{\rho}^{i} \neq 0$ & $t_{i \tau}+\Delta r=0$ & 4 & 0 & 0 & 0 & 0 \\
\hline$r_{\tau}=r_{o}$ & $L_{\rho}^{i}=0$ & $t_{i \tau}=0$ & 5 & 0 & 0 & 0 & 0 \\
\hline & $L_{\rho}^{i}<0$ & $t_{i \tau}+\Delta r<0$ & 6 & + & + & + & - \\
\hline$r_{\tau}<r_{o}$ & $L_{\rho}^{i}>0$ & $t_{i \tau}+\Delta r>0$ & 7 & + & - & $?$ & + \\
& & $t_{i \tau}+\Delta r<0$ & 8 & - & + & $?$ & - \\
\hline
\end{tabular}

*) $\Delta r:=r_{\tau}-r_{o}$

\section{Table 2: Transition from trade without taxation to tax competition}

Table 2 calls for some comments. The very first column lists the possible constellations of the respective equilibrium interest rates analogous to the top row in Table 1 . As in Table 1, each of the Cases 1 - 8 of Table 2 is characterized by the sign of $L_{\rho}^{i}$ (second column) but a new attribute is the sign of $t_{i \tau}+\Delta r$ (third column). The meaning and role of the term $t_{i \tau}+\Delta r$ is made precise in the proof of Proposition 7 in the Appendix. There we show that if the interest rate $r_{o}$ of the no-tax trade equilibrium prevails (rather than the interest rate $r_{\tau}$ of the taxcompetition equilibrium) and if all governments $j$ choose $t_{j \tau}+\Delta r$, then the allocation of the tax-competition equilibrium is attained. ${ }^{16}$

It is informative to combine the results of Table 2 with the information provided in Proposition 5. Recall from (11) that $L_{\rho}^{i}<0$ holds, in particular but not only, for Cobb-Douglas functions and CES functions satisfying $\sigma_{i}<c_{i}$. Yet if the technology is Cobb-Douglas, the Cases 1 and 2 apply only if the Cobb-Douglas functions differ across countries. Otherwise Case 4 applies. Case 5 represents a knife-edge case corresponding to the Cases 3 and 5 of Table 1 which happens to occur when all production functions are when all production functions are

\footnotetext{
${ }^{16}$ Consider for example the constellation $r_{\tau}>r_{o}$ (or $\Delta r=r_{\tau}-r_{o}>0$ ) and $L_{\rho}^{i}<0$ in Table 2. Owing to $L_{\rho}^{i}<0$ we have $t_{i \tau}<0$ such that $t_{j \tau}+\Delta r$ may take on either sign generating one of the Cases 1,2 or 4 .
} 
CES with $\sigma_{i}=c_{i}$. The properties of production functions leading to the Cases 6, 7 and 8 in Table 2 can be indentified in analogy to the properties on the Cases 1, 2 and 3.

Note finally that if $r_{\tau}>r_{o}$ and $L_{\rho}^{i}>0$ (Case 3), $t_{i \tau}+\Delta r<0$ is not a feasible outcome. If $r_{\tau}<r_{o}$ and $L_{\rho}^{i}<0$ (Case 6), $t_{i \tau}+\Delta r>0$ is not a feasible outcome either. A necessary condition for the Cases 3 and 6 to occur is that there are technologies exhibiting $Y_{k \ell}>0$ for some countries and $Y_{k \ell}<0$ for others.

In those special tax-competition equilibria in which the tax rates $t_{1 \tau}, \ldots, t_{n \tau}$ are uniform across countries (Case 4 and trivially Case 5 of Table 2) ${ }^{17}$ the allocations of the tax-competition equilibrium $E_{\tau}$ and the no-tax trade equilibrium $E_{o}$ coincide as a consequence of Proposition 1. Tax competition then has no allocative impact at all.

Consider next the tax incidence in the plausible case of tax competition where tax rates differ across countries. Focusing on employment we observe, rather unexpectedly, that variations in employment are clear in sign under all conditions: Unless tax rates are uniform (see above) employment either improves or shrinks. For either sign of the difference $r_{\tau}-r_{o}$ employment declines [increases] if $t_{i \tau} \cdot\left(t_{i \tau}+\Delta r\right)<0 \quad\left[t_{i \tau} \cdot\left(t_{i \tau}+\Delta r\right)>0\right]$. The constellation $t_{i \tau}<0$ and $\left(t_{i \tau}+\Delta r\right)>0$ or vice versa occurs under two conditions: (i) $t_{i \tau}$ and $r_{\tau}-r_{o}$ must exhibit opposite signs and (ii) $t_{i \tau}$ must be sufficiently close to zero.

While all signs of changes in factor inputs and income are clear, the changes in the level of output are ambiguous in the Cases 3,7 and 8 where $\operatorname{sign}\left(\ell_{i \tau}-\ell_{i o}\right) \cdot\left(k_{i \tau}-k_{i o}\right)$ is negative.

The striking result of Proposition 7 is that countries may lose from tax competition if the scenario of trade without taxation is taken as the baseline. Under the conditions specified in Proposition 7 country $i$ may suffer a welfare loss and such a loss can occur under various assumptions. Country i's technology may satisfy $Y_{k \ell}^{i}>0$ (Cases 2 and 6) or $Y_{k \ell}^{i}<0$ (Cases 3 and 8) or the constellation $r_{\tau}>r_{o}$ (Cases 2 and 3) or $r_{\tau}<r_{o}$ (Cases 6 and 8) may be given. To see the driving force for the welfare loss, consider Case 2 in Table 2 as an example. $t_{i \tau}+\Delta r$ will be positive, if country $i$ 's tax rate $t_{i \tau}$ is negative but relatively small in absolute value (see

\footnotetext{
${ }^{17}$ Case 4 applies, e.g., when all countries produce with identical Cobb-Douglas functions or when all countries produce with identical CES functions and their rigid wage rates are identical. See our comments on Proposition 5.
} 
the proof of Proposition 7) ${ }^{18}$. Hence in tax-competition equilibrium we find that $L^{i}\left(r_{\tau}+t_{i \tau}, w_{i}\right)=L^{i}\left(r_{o}+t_{i \tau}+\Delta r, w_{i}\right)<L^{i}\left(r_{o}, w_{i}\right)$ because $L_{\rho}^{i}<0$ is presupposed in Case 2, and $K^{i}\left(r_{\tau}+t_{i \tau}, w_{i}\right)=K^{i}\left(r_{o}+t_{i \tau}+\Delta r, w_{i}\right)<K^{i}\left(r_{o}, w_{i}\right)$ because $K_{\rho}^{i}<0$. The straightforward implication is that the output shrinks $\left(y_{i \tau}<y_{i o}\right)$. On the other hand, since $k_{i \tau}<k_{i o}$, country i's value of exports rises or the cost of its imports declines. However that partial income increase is smaller than the loss from reduced production because the per unit cost of capital as an input, $r_{o}+t_{i \tau}+\Delta r$, is higher than $r_{o}$, the per unit revenue from increased capital exports or from reduced capital imports.

\section{From autarky to tax competition}

Proposition 3 scrutinized the shift from autarky to the no-tax trade equilibrium and Proposition 7 analyzed the allocative impact of moving from the no-tax trade equilibrium to the taxcompetition equilibrium. It is therefore necessary combining both steps in an effort to answer the question what the allocative consequences are for individual countries of moving from autarky to tax competition. As for income changes, closer inspection of the Tables 1 and 2 reveals that the sign of those changes is unclear in several cases. Obviously, since the sign of the difference $x_{i o}-x_{i a}$ is unclear in the Cases 1 and 6 of Table 1, the net welfare change from autarky to tax competition is bound to be ambiguous. However, even if the partial welfare effects in the Tables 1 and 2 are clear in sign, the net effect is also ambiguous, whenever the partial effects exhibit opposite signs. Although it is not possible to fully exploit the complex information presented in the Propositions 3 and 7, we restrict our attention to changes in unemployment and welfare and select some specific cases in

Proposition 8 (Losses from autarky to tax competition).

Consider the transition of the n-country economy from autarky to tax competition.

(i) Country i suffers a welfare loss, if all countries use identical Cobb-Douglas production functions , (7), and if $\bar{k}_{i}>\omega_{i} \bar{k}_{\varnothing}$ holds.

\footnotetext{
${ }^{18}$ For example, if all production functions are Cobb-Douglas and differ across countries with respect to their parameter $\beta$, we conclude from $\Delta r>0$ (which is presupposed in Case 2) and $t_{i \tau}=-\beta_{i} r_{\tau}<0$ from equation (11) that $\tilde{t}_{i \tau}=t_{i \tau}+\Delta r=-\beta_{i} r_{\tau}+\Delta r>0$, if $\beta_{i}$ is a sufficiently small component in $\left(\beta_{1}, \beta_{2}, \ldots, \beta_{n}\right)$.
} 
(ii) Country i suffers a welfare loss, if the production functions satisfy $Y_{k \ell}^{i}>0$ for all i (as e.g. in case of Cobb-Douglas or CES with $\sigma_{i}<c_{i}$ ), if $r_{i a}=r_{o}$ and if $t_{i \tau}$ is small enough in absolute value relative to the other countries' optimal tax rates.

(iii) Country i suffers a welfare loss, if $r_{i a}>r_{o}$ (implying $k_{i o}>\bar{k}_{i}$ ), if its production function is CES satisfying $\sigma_{i}>c_{i}+\left(k_{i o}-\bar{k}_{i}\right)\left(w_{i}+r_{o} q_{i o}\right) / w_{i} k_{i o}$, and

- either if $Y_{k \ell}^{i}<0$ for all $i$ and $t_{i \tau}$ is small enough relative to the other countries' optimal tax rates,

- or if all countries use the same CES production function as country i and wage rates are the same across countries.

(iv) In all scenarios of the Propositions 8i, 8ii and 8iii country i suffers from increasing unemployment in the transition from autarky to tax competition.

The principal message of Proposition 8 is that capital market liberalization with tax competition can lead to rising unemployment and welfare losses under various conditions. Welfare losses can be derived by combining in various ways the countries' fundamentals, i.e. their wage rates, capital endowments and production technologies. It is conceded that all cases presented in Proposition 8 make use of conditions that are more or less restrictive. Yet all these conditions are sufficient but not necessary. In our view, it is therefore safe to conjecture that losses from tax competition are not an elusive phenomenon. Take for example Proposition 8ii. Its range - and relevance - is certainly limited because the condition $r_{i a}=r_{o}$ is very special, if it is fulfilled at all for any country. However, a welfare loss will also occur if the condition $r_{i a}=r_{o}$ of Proposition 8ii is replaced by $r_{i a} \neq r_{o}$ as long as if the difference $\left|r_{i a}-r_{o}\right|$ is small enough. When the condition $r_{i a}=r_{o}$ (Case 4 of Table 1) is weakened in this non-rigorous way, welfare losses can also be identified in the Cases 3, 6 and 8 of Table 2. Moreover, in all cases of uniform optimal tax rates which we identified in our remarks on equation (11) some countries lose when moving from autarky to tax competition, if and only if they lose in the transition from autarky to trade without taxation.

\section{Concluding remarks}

We have shown that unemployment markedly changes the impact of capital market liberalization and capital-tax competition among heterogeneous countries as compared to the case of 
perfectly competitive labor markets. With autarky as the reference scenario, the introduction of international capital mobility and tax competition turned out to have the potential of reducing the welfare and/or of exacerbating unemployment in some countries. Hence such countries will not be in favor of capital market liberalization unless they succeed in removing wage rigidity. Since we allowed countries to differ with respect to capital endowments, rigid wage rates and production technologies, there is a great variety of outcomes and welfare changes which can hardly be characterized completely. Nonetheless, we identified a number of specific cases where countries suffer higher unemployment and a welfare loss during the transition from autarky to tax competition and traced the reasons for that outcome. As could be expected, less general assumptions on production functions yielded more informative results. For example, in case of Cobb-Douglas technology we were able to fully characterize the allocative displacement effects. We showed that in the transition from autarky to tax competition countries fare the better, ceteris paribus, the greater is their capital endowment or the lower is their rigid wage rate.

The rigid-wage assumption is a very simple and coarse way to model unemployment given the great variety of sophisticated and complex theories of non-competitive wage formation developed in labor economics (Nickel 1990). One small step in relaxing that assumption in future research work would be to retain downward rigidity but allow for upward flexible wages. More complex and arguably more realistic labor market theories have already been employed in some studies of capital-tax competition with labor-markets imperfections some of which we have referenced in the Introduction. However, as we pointed out, none of these studies tackles unemployment and heterogeneous countries. The trade-off between realistic complexity in modeling, tractability and informative insights appears to necessitate and warrant compromises.

\section{References}

Aloi, M., Leite-Monteiro, M., and Lloyd-Braga, T. (2009), "Unionized labor markets and globalized capital markets", Journal of International Economics 78, 149-153

Aronsson, T., and Wehke, S. (2008), "Public goods, unemployment and policy coordination", Regional Science and Urban Economics 38, 285-298

Bergström, V., and Panas, E. E. (1992), "How robust is the capital-skill complementarity hypothesis?", The Review of Economics and Statistics 74, 540-546 
Bucovetsky, S. (1991), "Asymmetric tax competition", Journal of Urban Economics 30, $171-181$

DePater, J. A., and Myers, G. M. (1994), "Strategic capital tax competition: A pecuniary externality and a corrective device", Journal of Urban economics 36, 66-78

Duffy, J., Papageorgiou, C. and Perez-Sebastian, F. (2004), "Capital-skill complementarity? Evidence from a panel of countries", The Review of Economics and Statistics 86, 327344

Eaton, J., and Panagariya, A. (1979), "Gains from trade under variable returns to scale, commodity taxation, tariffs and factor market distortions", Journal of International Economics 9, 481-501

Eggert, W., and Goerke, L. (2004), "Fiscal policy, economic integration and unemployment", Journal of Economics 82, 137-167

Fuest, C., and Huber, B. (1999), "Tax coordination and unemployment", International Tax and Public Finance 6, 7-26

Griliches, Z. (1969), "Capital-skill complementarity", The Review of Economics and Statistics $51,465-468$

Kemp, M., and Negishi, T. (1970), "Variable returns to scale, commodity taxes, factor market distortions and their implications for trade gains", The Swedish Journal of Economics $72,1-11$

Kessler, A.S., Lülfesmann, C., and Myers, G. M. (2003), "Economic versus political symmetry and the welfare concern with market integration and tax competition", Journal of Public Economics 87, 847-865

Leite-Monteiro, M., Marchand, M., and Pestieau, P. (2003), "Employment subsidy with capital mobility", Journal of Public Economic Theory 5, 327-344

Lockwood, B., and Makris, M. (2006), "Tax incidence, majority voting and capital market integration", Journal of Public Economics 90, 1007-1025

Nickell, S. (1990), "Unemployment: A survey", Economic Journal 100, 391-439

Ogawa, H., Sato, Y., and Tamai, T. (2006), "A note on unemployment and capital tax competition", Journal of Urban Economics 60, 350-356 
Peralta, S., and van Ypersele, T. (2005), "Factor endowments and welfare levels in an asymmetric tax competition game", Journal of Urban Economics 57, 258-274

Sato, Y., and Thisse, J.-F. (2007), "Competing for capital when labor is heterogeneous", European Economic Review 51, 2054-2079

Wilson, J. D. (1986), "A theory of interregional tax competition", Journal of Urban Economics 19, 296-315

Wilson, J. D. (1991), "Tax competition with interregional differences in factor endowments", Regional Science and Urban Economics 21, 423-451

Zodrow, G. R., and Mieszkowski, P. (1986), "Pigou, Tiebout, property taxation, and the underprovision of local public goods", Journal of Urban Economics 19, 356-370

\section{Appendix}

Proof of Proposition 1. In the tax-competition equilibrium

$E_{\tau}:=\left\{t_{1 \tau}, \ldots, t_{n \tau}, r_{\tau},\left(x_{i \tau}, y_{i \tau}, k_{i \tau}, \ell_{i \tau}\right)_{i=1, \ldots, n}\right\}$ the capital market is in equilibrium, by presupposition: $\sum_{j} \bar{k}_{j}=\sum_{j} K^{j}\left(r_{\tau}+t_{j \tau}, w_{j}\right)$. Consider $\left.\theta \in\right]-\infty, r\left[\right.$ and define $\tilde{t}_{i \tau}:=t_{i \tau}+\theta$ for all $i$ and $\tilde{r}_{\tau}:=r_{\tau}-\theta$. Then we obviously have $\sum_{j} \bar{k}_{j}=\sum_{j} K^{j}\left(r_{\tau}+t_{j \tau}, w_{j}\right)=\sum_{j} K^{j}\left(\tilde{r}_{\tau}+\tilde{t}_{j \tau}, w_{j}\right)$.

Proof of Proposition 2. Under conditions of perfect competition the elasticity of substitution reads $\sigma_{i}=\frac{d q_{i}}{q_{i}} \cdot \frac{w_{i} / r}{d\left(w_{i} / r\right)}$, where $q_{i}:=\frac{k_{i}}{\ell_{i}}$. Rearrange this equation to obtain $\sigma_{i} \hat{w}_{i}-\sigma_{i} \hat{r}_{i}=\hat{q}_{i}$.

Furthermore, consider $\hat{q}_{i}=\hat{k}_{i}-\hat{\ell}_{i}$ as well as $\hat{\ell}_{i}=-\frac{c_{i} w_{i}+q_{i} r_{i} \sigma_{i}}{w_{i}+q_{i} r_{i}} \hat{w}_{i}-\frac{\left(c_{i}-\sigma_{i}\right) q_{i} r_{i}}{w_{i}+q_{i} r_{i}} \hat{r}_{i} \quad$ in $\sigma_{i} \hat{w}_{i}-\sigma_{i} \hat{r}_{i}=\hat{q}_{i}$ to obtain after some rearrangements of terms

$$
\hat{r}_{i}=-\frac{w_{i}+q_{i} r_{i}}{\sigma_{i} w_{i}+c_{i} q_{i} r_{i}} \hat{k}_{i}+\frac{\left(\sigma_{i}-c_{i}\right) w_{i}}{\sigma_{i} w_{i}+c_{i} q_{i} r_{i}} \hat{w}_{i}
$$

where $c_{i}:=1 /\left(1-b_{i}\right)>1$. If we set $k_{i}=\overline{k_{i}}$ and hence $\hat{k}_{i}=\hat{\overline{k_{i}}}$ in that equation, $r_{i}=r_{i a}$ and $\hat{r}_{i}=\hat{r}_{i a}$ follows. That proves Proposition 2 . 
Proof of Proposition 3. Proposition 3i: Denote by $x_{i}$ and $x_{i a}$ the national incomes when the interest rate is $r$ and $r_{i a}$, respectively. Obviously, that implies $x_{i}=x_{i a}$ for $r=r_{i a}$, and if $d x_{i} / d r$ is monotone in $r$ we are able to determine the sign of the difference $x_{i o}-x_{i a}$. Differentiation of $x_{i}$ with respect to $r$ yields

$$
\frac{d x_{i}}{d r}=w_{i} L_{r}^{i}-\left(k_{i}-\bar{k}_{i}\right)
$$

and $\left.\frac{d x_{i}}{d r}\right|_{r=r_{i a}}=w_{i} L_{r}^{i}$. Suppose that $r>r_{i a}$ and $L_{r}^{i}>0$. Then $k_{i}=K^{i}\left(r, w_{i}\right)<K^{i}\left(r_{i a}, w_{i}\right)=\bar{k}_{i}$ and therefore $\frac{d x_{i}}{d r}>0$, proving $x_{i o}>x_{i a}$ for the case 2 in Table 1 . Along the same lines we show that $x_{i o}>x_{i a}$ in the cases 3 and 7 and $x_{i o}<x_{i a}$ in case 5 in Table 1 . In the cases 1 and 6 the sign of $d x_{i} / d r$ is unclear.

Proposition 3ii: (a) We first observe that the term $y_{i}-r_{i} k_{i}$ turns into $y_{i}-r_{i} k_{i}=\ell_{i}^{b} q_{i}^{\alpha}-r_{i} k_{i}=$ $k_{i}\left(\ell_{i}^{b} k_{i}^{-1} q_{i}^{\alpha}-r_{i}\right)$ when the production function is Cobb-Douglas. Interest rates $r_{i}$ may differ across countries in autarky but they are uniform in the associated zero-tax equilibrium. We also know that $\ell_{i}^{b} k_{i}^{-1} q_{i}^{\alpha}=\ell_{i}^{b} k_{i}^{-1} \frac{k_{i}}{\ell_{i}} q_{i}^{\alpha-1}=\ell_{i}^{b-1} q_{i}^{\alpha-1}=\frac{r_{i}}{\alpha}$, because $\alpha \ell_{i}^{b-1} q_{i}^{\alpha-1}=r_{i}$ is the firstorder condition for profit maximization. Hence $y_{i}-r_{i} k_{i}=k_{i}\left(\frac{r_{i}}{\alpha}-r_{i}\right)=\frac{r_{i} k_{i}}{\alpha \gamma}$, where $\gamma:=\frac{1}{1-\alpha}$.

From this information the equations

$$
\left[Y^{i}\left(k_{i o}, \ell_{i o}\right)-r_{o} k_{i o}\right]=\frac{r_{o} k_{i o}}{\alpha \gamma} \quad \text { and } \quad\left[Y^{i}\left(\bar{k}, \ell_{i a}\right)-r_{i a} \bar{k}_{i}\right]=\frac{r_{i a} \bar{k}_{i}}{\alpha \gamma}
$$

follow, where the indexes $a$ and $o$ refer to the autarky equilibrium and the zero-tax equilibrium, respectively. We write the difference in income of country $i$ following a switch from autarky to free-trade as $\Delta x_{i}=x_{i o}-x_{i a}=\left[Y^{i}\left(k_{i o}, \ell_{i o}\right)-r_{o} k_{i o}\right]-\left[Y^{i}\left(\bar{k}, \ell_{i a}\right)-r_{i a} \bar{k}_{i}\right]-\left(r_{i a}-r_{o}\right) \bar{k}_{i}$ and consider (A2) to obtain $\alpha \gamma \Delta x_{i}=r_{o} k_{i o}-r_{i a}(1+\alpha \gamma) \bar{k}_{i}+\alpha \gamma r_{o} \bar{k}_{i}=r_{o}\left(k_{i o}-\bar{k}_{i}\right)+r_{o}(1+\alpha \gamma) \bar{k}_{i}-$ $r_{i a}(1+\alpha \gamma) \bar{k}_{i}$ or

$$
\alpha \gamma \Delta x_{i}=r_{o}\left(k_{i o}-\bar{k}_{i}\right)+(1+\alpha \gamma) \bar{k}_{i}\left(r_{o}-r_{i a}\right)
$$


(b) Next we determine the variables $r_{i a}, r_{o}$ and $k_{i o}$ for the Cobb-Douglas production function. The first-order conditions for profit maximization $r=\alpha k_{i}^{\alpha-1} l_{i}^{\beta}$ and $w_{i}=\beta k_{i}^{\alpha} l_{i}^{\beta-1}$ imply $\ell_{i}=\frac{\beta r_{i}}{\alpha w_{i}} k_{i}$ yielding

$$
r_{i}^{1-\beta}-\alpha^{1-\beta} \beta^{\beta} w_{i}^{-\beta} k_{i}^{-\frac{1}{c}}=0 \text {, where } c:=\frac{1}{1-b} .
$$

In autarky, we have $k_{i a}=\bar{k}_{i}$ such that (A4) is turned into

$$
r_{i a}=\alpha \beta^{\frac{\beta}{1-\beta}} w_{i}^{-\frac{\beta}{1-\beta}} \bar{k}_{i}^{-\frac{1}{(1-\beta) c}}
$$

In case of free trade we convert (A4) into $k_{i o}=\alpha^{(1-\beta) c} \beta^{\beta c} r_{o}^{-(1-\beta) c} w_{i}^{-\beta c}$. Invoke the equilibrium condition on the world capital market, $\sum_{j} k_{j o}=\sum_{j} \bar{k}_{j}$, to obtain $\sum_{j} k_{j o}=\sum_{j} \bar{k}_{j}=$ $\alpha^{(1-\beta) c} \beta^{\beta c} r_{o}^{-(1-\beta) c} \sum_{j} w_{j}^{-\beta c}$ or, equivalently, $\bar{k}_{\varnothing}:=\frac{\sum_{j} \bar{k}_{j}}{n}=\alpha^{(1-\beta) c} \beta^{\beta c} r_{o}^{-(1-\beta) c} \sum_{j}\left(\frac{w_{j}^{-\beta c}}{n}\right)$ and

$$
r_{o}^{1-\beta}=\alpha^{1-\beta} \beta^{\beta}\left(\sum_{j} \frac{w_{j}^{-\beta c}}{n}\right)^{\frac{1}{c}} \cdot \bar{k}_{\varnothing}^{-\frac{1}{c}} \text { or } r_{o}=\alpha \beta^{\frac{\beta}{1-\beta}}\left(\sum_{j} \frac{w_{j}^{-\beta c}}{n}\right)^{\frac{1}{(1-\beta) c}} \cdot \bar{k}_{\varnothing}^{-\frac{1}{(1-\beta) c}}
$$

To determine $k_{\text {io }}$ we combine (A4) and (A6) which yields, after some rearrangement of terms,

$$
k_{i o}=\omega_{i} \bar{k}_{\varnothing}, \quad \text { where } \omega_{i}:=\frac{n w_{i}^{-\beta c}}{\sum_{j} w_{j}^{-\beta c}} .
$$

(c) Invoke $r_{i a}$ from (A5) and $r_{o}$ from (A6) combined with (A7) and observe that

$$
r_{o} \geq r_{i a} \Leftrightarrow \alpha \beta^{\frac{\beta}{1-\beta}} w_{i}^{-\frac{\beta}{1-\beta}} \cdot\left(\omega_{i} \bar{k}_{\varnothing}\right)^{-\frac{1}{(1-\beta) c}} \geq \alpha \beta^{\frac{\beta}{1-\beta}} w_{i}^{-\frac{\beta}{1-\beta}} \bar{k}_{i}^{-\frac{1}{(1-\beta) c}} \Leftrightarrow \omega_{i} \bar{k}_{\varnothing} \leq \bar{k}_{i} .
$$

(d) We now insert (A5), (A6) and (A7) in (A3):

$$
\alpha \gamma \Delta x_{i}=r_{o} \bar{k}_{\varnothing}\left[\omega_{i}-\kappa_{i}\right]+\frac{(1+\alpha \gamma) \bar{k}_{i} \alpha \beta^{\frac{\beta}{1-\beta}}}{\bar{k}_{\varnothing}^{\frac{1}{(1-\beta) c}} w_{i}^{\frac{\beta}{1-\beta}}}\left[\omega_{i}^{-\frac{1}{(1-\beta) c}}-\kappa_{i}^{-\frac{1}{(1-\beta) c}}\right]
$$




$$
=\delta_{i}\left[\omega_{i} \bar{k}_{\varnothing}^{1-\frac{1}{(1-\beta) c}}+\alpha \gamma \bar{k}_{i} \bar{k}_{\varnothing}^{-\frac{1}{(1-\beta) c}}\right]-(1+\alpha \gamma) \bar{k}_{i} r_{i a}
$$

where $\delta_{i}:=\frac{\alpha \beta^{\frac{\beta}{1-\beta}}}{\omega_{i}^{(1-\beta) c} w_{i}^{\frac{\beta}{1-\beta}}}$ and $\kappa_{i}:=\frac{\bar{k}_{i}}{\bar{k}_{\varnothing}}$. From (A9) it is straightforward that $\Delta x_{i}=0$, if $\omega_{i}=\kappa_{i}$ or $\omega_{i} \bar{k}_{\varnothing}=\bar{k}_{i}$. To specify how $\alpha \gamma \Delta x_{i}$ responds to changes in $\bar{k}_{\varnothing}$ consider the derivatives of (A9)

$$
\begin{aligned}
& \frac{d\left(\alpha \gamma \Delta x_{i}\right)}{d \bar{k}_{\varnothing}}=\frac{\alpha \delta_{i}}{1-\beta} \cdot \bar{k}_{\varnothing}^{-\frac{1}{(1-\beta) c}-1}\left(\omega_{i} \bar{k}_{\varnothing}-\frac{1-b}{1-\alpha} \bar{k}_{i}\right) \\
& \frac{d^{2}\left(\alpha \gamma \Delta x_{i}\right)}{d \bar{k}_{\varnothing}^{2}}=\frac{\alpha \delta_{i}}{(1-\beta)^{2} c} \bar{k}_{\varnothing}^{-\frac{1}{(1-\beta) c}}-2\left[\left(\frac{1-\beta}{1-\alpha}+\frac{1-b}{1-\alpha}\right) \bar{k}_{i}-\omega_{i} \bar{k}_{\varnothing}\right] .
\end{aligned}
$$

These derivatives imply

$\frac{d\left(\alpha \gamma \Delta x_{i}\right)}{d \bar{k}_{\varnothing}} \geq 0 \Leftrightarrow \omega_{i} \bar{k}_{\varnothing} \geq \frac{1-b}{1-\alpha} \bar{k}_{i} \quad$ and $\quad \frac{d^{2}\left(\alpha \gamma \Delta x_{i}\right)}{d \bar{k}_{\varnothing}^{2}} \geq 0 \Leftrightarrow\left(\frac{1-\beta}{1-\alpha}+\frac{1-b}{1-\alpha}\right) \bar{k}_{i} \geq \omega_{i} \bar{k}_{\varnothing}$.

$\frac{d\left(\alpha \gamma \Delta x_{i}\right)}{d \bar{k}_{\varnothing}}=0$ is attained for $\bar{k}_{\varnothing}=\frac{1-b}{1-\alpha} \cdot \frac{\bar{k}_{i}}{\omega_{i}}$ and inserting $\bar{k}_{\varnothing}=\frac{1-b}{1-\alpha} \cdot \frac{\bar{k}_{i}}{\omega_{i}}$ in (A11) yields $\frac{d^{2}\left(\alpha \gamma \Delta x_{i}\right)}{d \bar{k}_{\varnothing}^{2}}=\frac{\alpha \delta_{i}}{(1-\beta)^{2} c} \bar{k}_{\varnothing}^{-\frac{1}{(1-\beta) c}-2} \bar{k}_{i} \frac{1-\beta}{1-\alpha}>0$. Hence $\alpha \gamma \Delta x_{i}$ attains its unique minimum at $\bar{k}_{\varnothing}=\frac{1-b}{1-\alpha} \cdot \frac{\bar{k}_{i}}{\omega_{i}}<\frac{\bar{k}_{i}}{\omega_{i}}$. We have shown above that $\Delta x_{i}=0$, if $\bar{k}_{\varnothing}=\frac{\bar{k}_{i}}{\omega_{i}}$. For this value of $\bar{k}_{\varnothing}$ (A10) turns into $\frac{d\left(\alpha \gamma \Delta x_{i}\right)}{d \bar{k}_{\varnothing}}=\frac{\alpha \beta \gamma \delta_{i}}{1-\beta} \cdot \bar{k}_{\varnothing}^{-\frac{1}{(1-\beta) c}-1} \bar{k}_{i}>0$. Therefore, at its minimum $\alpha \gamma \Delta x_{i}$ is negative. Moreover, since $\Delta x_{i}<0$ for $\bar{k}_{\varnothing}=0$ according to (A9), we conclude that $\Delta x_{i}>0$ for $\left.\bar{k}_{i} \in\right] 0, \omega_{i} \bar{k}_{\varnothing}\left[, \Delta x_{i}=0\right.$ for $\bar{k}_{i}=\omega_{i} \bar{k}_{\varnothing}$ and $\Delta x_{i}<0$ for $\left.\bar{k}_{i} \in\right] \omega_{i} \bar{k}_{\varnothing}, n \omega_{i} \bar{k}_{\varnothing}[$.

Proposition 3iii: In Case $6 \frac{d x_{i}}{d r}=w_{i} L_{r}^{i}-\left(k_{i}-\bar{k}_{i}\right)>0$ for all $r \in\left[r_{o}, r_{i a}\right]$ is sufficient for $x_{i o}<x_{i a}$. Since CES implies $L_{r}^{i}=\frac{\left(\sigma_{i}-c_{i}\right) k_{i}}{w_{i}+r q_{i}}$ we find that $\frac{d x_{i}}{d r}>0$ holds, if for all $r \in\left[r_{o}, r_{i a}\right]$ 


$$
\sigma_{i}>c_{i}+\frac{k_{i}-\overline{k_{i}}}{\phi_{i} k_{i}} \text { where } \phi_{i}:=\frac{w_{i}}{w_{i}+r q_{i}} \text { and } q_{i}:=\left(\frac{a_{k i}}{a_{\ell i}}\right)^{\sigma_{i}}\left(\frac{w_{i}}{r}\right)^{\sigma_{i}} \text {. }
$$

Since $\frac{k_{i}-\bar{k}_{i}}{k_{i}}$ is decreasing and $\phi_{i}$ is increasing in $r$, it follows that $\frac{k_{i o}-\bar{k}_{i}}{\phi_{i a} k_{i o}} \geq \frac{k_{i}-\bar{k}_{i}}{\phi_{i} k_{i}}$ for all $r \in\left[r_{o}, r_{i a}\right]$. That proves Proposition 3iii.

Proof of Proposition 4. The strategy of proof is similar to that of Proposition 3ii. Country i's income is $x_{i a}=y_{i a}=\bar{k}_{i}^{\alpha} m_{i}^{\beta}$ in autarky and

$$
x_{i o}=y_{i o}-r_{o}\left(k_{i o}-\bar{k}_{i}\right)=k_{i o}^{\alpha} m_{i}^{\beta}-r_{o}\left(k_{i o}-\bar{k}_{i}\right)
$$

under free trade. In the latter case profit maximization implies

$$
r_{o}=\alpha k_{i o}^{\alpha-1} m_{i}^{\beta}
$$

Combining (A12) and (A13) yields $x_{i o}=k_{i o}^{\alpha} m_{i}^{\beta}-\alpha k_{i o}^{\alpha-1} m_{i}^{\beta} k_{i o}+\alpha k_{i o}^{\alpha-1} m_{i}^{\beta} \bar{k}_{i}=(1-\alpha) k_{i o}^{\alpha} m_{i}^{\beta}+$ $\alpha \bar{k}_{i} k_{i o}^{\alpha-1} m_{i}^{\beta}$. Hence

$$
\Delta x_{i}=x_{i o}-x_{i a}=(1-\alpha) k_{i o}^{\alpha} m_{i}^{\beta}+\alpha \bar{k}_{i} k_{i o}^{\alpha-1} m_{i}^{\beta}-\bar{k}_{i}^{\alpha} m_{i}^{\beta} .
$$

Next we show that $k_{i o}=\bar{m}_{i} \bar{k}_{\varnothing}$. From (A13) we have $k_{i o}=\left(\frac{r_{o}}{\alpha m_{i}^{\beta}}\right)^{-\frac{1}{1-\alpha}}$. Invoking $\sum_{j} k_{j o}=\sum_{j} \bar{k}_{j}$ from (5) yields $\left(\frac{r_{o}}{\alpha}\right)^{-\frac{1}{1-\alpha}} \sum_{j} m_{j}^{\frac{\beta}{1-\alpha}}=\sum_{j} \bar{k}_{j}, \quad \bar{k}_{\varnothing}=\frac{1}{n}\left(\frac{r_{o}}{\alpha}\right)^{-\frac{1}{1-\alpha}} \sum_{j} m_{j}^{\frac{\beta}{1-\alpha}}$ and $r_{o}=\alpha\left(\sum_{j} m_{j}^{\frac{\beta}{1-\alpha}}\right)^{1-\alpha} \cdot\left(n \bar{k}_{\varnothing}\right)^{-(1-\alpha)}$. Insert $r_{o}$ from the last equation in $k_{i o}=\left(\frac{r_{o}}{\alpha m_{i}^{\beta}}\right)^{-\frac{1}{1-\alpha}}$ to obtain $k_{i o}=\bar{m}_{i} \bar{k}_{\varnothing}$. Use this information to turn (A14) into

$$
\Delta x_{i}=(1-\alpha) \bar{m}_{i}^{\alpha} \bar{k}_{\varnothing}^{\alpha} m_{i}^{\beta}+\alpha \bar{k}_{i} \bar{m}_{i}^{\alpha-1} \bar{k}_{\varnothing}^{\alpha-1} m_{i}^{\beta}-\bar{k}_{i}^{\alpha} m_{i}^{\beta}
$$

It is straightforward from (A15) that $\Delta x_{i}=0$ if $\bar{k}_{i}=\bar{m}_{i} \bar{k}_{\varnothing}$. To specify how $\Delta x_{i}$ responds to changes in $\bar{k}_{i}$ when $\bar{k}_{\varnothing}$ is kept constant, consider the derivatives of (A15),

$$
\frac{d \Delta x_{i}}{d \bar{k}_{\mathrm{i}}}=\alpha m_{i}^{\beta}\left(\bar{m}_{i}^{\alpha-1} \bar{k}_{\varnothing}^{\alpha-1}-\bar{k}_{i}^{\alpha-1}\right) \quad \text { and } \quad \frac{d^{2} \Delta x_{i}}{d \bar{k}_{\mathrm{i}}^{2}}=\alpha(1-\alpha) m_{i}^{\beta} \bar{k}^{\alpha-2} \text {. }
$$


Since the first derivative implies $\frac{d \Delta x_{i}}{d \bar{k}_{i}} \geq 0 \Leftrightarrow \bar{m}_{i} \bar{k}_{\varnothing} \geq \bar{k}_{i}$ and $\frac{d^{2} \Delta x_{i}}{d \bar{k}_{i}}>0, \Delta x_{i}$ from (A15) attains its unique minimum at $\bar{k}_{i}=\bar{m}_{i} \bar{k}_{\varnothing}$.

Proof of Proposition 5. Equation (10) is straightforward from the first-order condition of maximizing (4) with respect to $t_{i}: X_{t}^{i}=Y_{k}^{i} K_{\rho}^{i}+Y_{l}^{i} L_{\rho}^{i}-r K_{\rho}^{i}=\left(\rho_{i}-r\right) K_{\rho}^{i}+w_{i} L_{\rho}^{i}=$ $t_{i} K_{\rho}^{i}+w_{i} L_{\rho}^{i}=0$. (11) follows from combining the equation (10) with (6) and (7) and the pertaining factor demand functions.

Proof of Proposition 6. Suppose that $L_{\rho}^{i}<0$ and hence $t_{i \tau}<0$. Starting from $t_{i}=0$, successive reductions of $t_{i}$ decrease $\rho=r_{o}+t_{i}$ and therefore increase $L^{i}\left(r_{o}+t_{i}, w_{i}\right)$. Suppose next that $L_{\rho}^{i}>0$ and hence $t_{i \tau}>0$. Starting from $t_{i}=0$ successive increases in $t_{i}$ increase $\rho=r_{o}+t_{i}$ and therefore also increase $L^{i}\left(r_{o}+t_{i}, w_{i}\right)$.

Proof of Proposition 7. The proof proceeds in several steps. First we prove the

Claim: Associated with the equilibrium $E_{\tau}$ is an 'auxiliary' constant-tax trade equilibrium ${ }^{19}$ $\tilde{E}_{\tau}:=\left\{\tilde{t}_{1 \tau}, \ldots, \tilde{t}_{n \tau}, \tilde{r}_{\tau},\left(\tilde{x}_{i \tau}, \tilde{y}_{i \tau}, \tilde{k}_{i \tau}, \tilde{\ell}_{i \tau}\right)_{i=1, \ldots, n}\right\}$ with the following properties:

(a) $\left(\tilde{x}_{i \tau}, \tilde{y}_{i \tau}, \tilde{k}_{i \tau}, \tilde{\ell}_{i \tau}\right)_{i=1, \ldots, n}=\left(x_{i \tau}, y_{i \tau}, k_{i \tau}, \ell_{i \tau}\right)_{i=1, \ldots, n},\left(\tilde{t}_{1 \tau}, \ldots, \tilde{t}_{n \tau}\right)=\left(t_{1 \tau}+\Delta r, \ldots, t_{n \tau}+\Delta r\right)$, $\Delta r=r_{\tau}-r_{o}$ and hence $\tilde{r}_{\tau}=r_{\tau}-\Delta r=r_{o}$.

(b) $\left(\tilde{t}_{1 \tau}, \ldots, \tilde{t}_{n \tau}\right)$ in $\tilde{E}_{\tau}$ contains positive and negative tax rates, if the tax rates $t_{1 \tau}, \ldots, t_{n \tau}$ in $E_{\tau}$ differ across countries; otherwise $\tilde{t}_{1 \tau}=\ldots=\tilde{t}_{n \tau}=0$.

The existence of the constant-tax trade equilibrium $\tilde{E}_{\tau}:=\left\{\tilde{t}_{1 \tau}, \ldots, \tilde{t}_{n \tau}, \tilde{r}_{\tau},\left(\tilde{x}_{i \tau}, \tilde{y}_{i \tau}, \tilde{k}_{i \tau}, \tilde{\ell}_{i \tau}\right)_{i=1, \ldots, n}\right\}$ as defined in part (a) of the Claim follows immediately from Proposition 1. Note that (5) implies $\sum_{j} \bar{k}_{j}=\sum_{j} K^{j}\left(r_{o}, w_{j}\right)=\sum_{j} K^{j}\left(r_{\tau}+t_{j \tau}, w_{j}\right)=\sum_{j} K^{j}\left(r_{\tau}-\Delta r+t_{j \tau}+\Delta r, w_{i}\right)=$ $\sum_{j} K^{j}\left(r_{o}+\tilde{t}_{j \tau}, w_{i}\right)$. Part (b) of the Claim postulates that if tax rates $t_{1 \tau}, \ldots, t_{n \tau}$ differ across

${ }^{19} \tilde{E}_{\tau}$ provides the information about the tax rates needed for shifting from the no-tax trade equilibrium allocation to the tax-competition equilibrium allocation while keeping unchanged the interest rate prevailing in the notax trade equilibrium. 
countries, the tax rates $\tilde{t}_{1 \tau}, \ldots, \tilde{t}_{n \tau}$ need to contain negative and positive components. Suppose not. Then sign $\tilde{t}_{\min }^{\tau}=\operatorname{sign} \tilde{t}_{\max }^{\tau}$ with $\tilde{t}_{\min }^{\tau} \neq 0$ or $\tilde{t}_{\max }^{\tau} \neq 0$, where $\tilde{t}_{\min }^{\tau}$ and $\tilde{t}_{\max }^{\tau}$ are the minimum and maximum components of $\left(\tilde{t}_{1 \tau}, \ldots, \tilde{t}_{n \tau}\right)$, respectively. That obviously implies $\sum_{j} \bar{k}_{j}=$ $\sum_{j} K^{j}\left(r_{o}, w_{j}\right) \neq \sum_{j} K^{j}\left(r_{o}+\tilde{t}_{j \tau}, w_{j}\right)$ contradicting the fact that $\tilde{E}_{\tau}$ is an equilibrium. If the tax rates $t_{1 \tau}, \ldots, t_{n \tau}$ are uniform across countries, the (associated) tax rates $\tilde{t}_{1 \tau}, \ldots, \tilde{t}_{n \tau}$ are also uniform because by definition of $\tilde{t}_{i \tau}$ it is true that $\tilde{t}_{i \tau}:=\Delta r+t_{i \tau}$ for all $i$ and satisfy $\tilde{t}_{1 \tau}=\ldots=\tilde{t}_{n \tau}=0$ by construction of $\tilde{E}_{\tau}$. This completes the proof of the Claim.

With this information we proceed to establish Proposition 7. We first focus on the change in employment induced by moving from $E_{o}$ to $E_{\tau}$ by proving the equivalence

$$
\left(t_{i \tau} \cdot \tilde{t}_{i \tau}\right)\left\{\begin{array}{l}
\geq \\
<
\end{array}\right\} 0 \Leftrightarrow L^{i}\left(r_{o}+\tilde{t}_{i \tau}, w_{i}\right)=L^{i}\left(r_{\tau}+t_{i \tau}, w_{i}\right)\left\{\frac{\geq}{<}\right\} L^{i}\left(r_{o}, w_{i}\right) .
$$

Consider the case that $t_{i \tau} \leq 0$ and $\tilde{t}_{i \tau} \leq 0$. We know that $t_{i \tau} \leq 0 \Leftrightarrow L_{\rho}^{i} \leq 0$ and therefore $L^{i}\left(r_{o}+\tilde{t}_{i \tau}, w_{i}\right) \geq L^{i}\left(r_{o}, w_{i}\right)$. Similarly, if $t_{i \tau} \geq 0$ and $\tilde{t}_{i \tau} \geq 0$, we have $t_{i \tau} \geq 0 \Leftrightarrow L_{\rho}^{i} \geq 0$ and therefore $L^{i}\left(r_{o}+\tilde{t}_{i \tau}, w_{i}\right) \geq L^{i}\left(r_{o}, w_{i}\right)$ as well. Based on this information it is straightforward to show that $\left(t_{i \tau} \cdot \tilde{t}_{i \tau}\right) \leq 0 \Leftrightarrow L^{i}\left(r_{o}+\tilde{t}_{i \tau}, w_{i}\right) \leq L^{i}\left(r_{o}, w_{i}\right)$.

The sign of the difference $k_{i \tau}-k_{i o}$ (second column of Table 2) is easily calculated as being equal to the sign of $\left(\tilde{t}_{i \tau} \cdot K_{\rho}^{i}\right)$, since $K_{\rho}^{i}<0$.

It remains to prove the signs in the last column of Table 2. Set $\rho_{i}=r_{o}+\tilde{t}_{i \tau}$ and differentiate $x_{i}=y_{i}-r_{o} k_{i}+r_{o} \bar{k}_{i}$ with respect to $\tilde{t}_{i \tau}$ :

$$
\frac{d x_{i}}{d \tilde{t}_{i \tau}}=Y_{k}^{i} K_{\rho}^{i}+Y_{\ell}^{i} L_{\rho}^{i}-r_{o} K_{\rho}^{i}=\tilde{t}_{i \tau} K_{\rho}^{i}+w_{i} L_{\rho}^{i}=\left(\tilde{t}_{i \tau}+\frac{w_{i} L_{\rho}^{i}}{K_{\rho}^{i}}\right) K_{\rho}^{i}
$$

From $\left.\frac{d x_{i}}{d \tilde{t}_{i \tau}}\right|_{\tilde{t}_{i \tau}=0}=w_{i} L_{r}^{i}$ follows sign $\left.\frac{d x_{i}}{d \tilde{t}_{i \tau}}\right|_{\tilde{t}_{i \tau}=0}=\operatorname{sign} L_{r}^{i}$ and if $d x_{i} / d \tilde{t}_{i \tau}$ is monotone in $\tilde{t}_{i \tau}$ we are able to determine the sign of the difference $x_{i \tau}-x_{i o}$. Combine $w_{i} L_{\rho}^{i} / K_{\rho}^{i}$ from (A16) with $r_{o}+\tilde{t}_{i \tau}=r_{\tau}+t_{i \tau}$ to obtain $\frac{w_{i} L_{\rho}^{i}}{K_{\rho}^{i}}=\frac{w_{i} L_{\rho}^{i}\left(r_{o}+\tilde{t}_{i \tau}, w_{i}\right)}{K_{\rho}^{i}\left(r_{o}+\tilde{t}_{i \tau}, w_{i}\right)}=\frac{w_{i} L_{\rho}^{i}\left(r_{\tau}+t_{i \tau}, w_{i}\right)}{K_{\rho}^{i}\left(r_{\tau}+t_{i \tau}, w_{i}\right)}=-t_{i \tau}$ and hence 


$$
\frac{d x_{i}}{d \tilde{t}_{i \tau}}=\left(\tilde{t}_{i \tau}-t_{i \tau}\right) K_{\rho}^{i}=\left(r_{\tau}-r_{o}\right) K_{\rho}^{i}
$$

We conclude from (A17) that

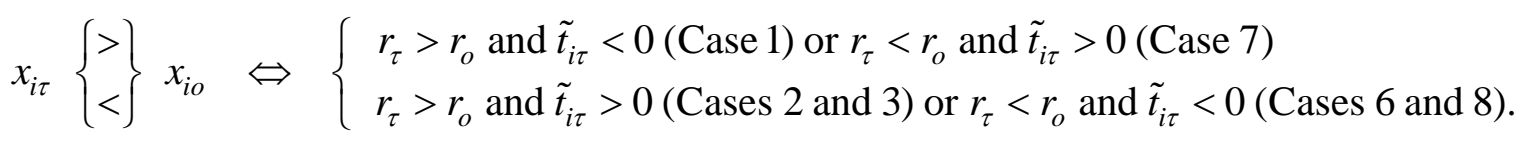

The Case 4 in Table 2 is obvious.

Proof of Proposition 8. Proposition 8i follows from combining Case 1 of Table 1 with Case 4 of Table 2 and Proposition 3ii. Proposition 8ii follows from combining Case 4 of Table 1 with Case 2 of Table 2. The first part of Proposition 8iii follows from combining Case 6 of Table 1 with Case 8 of Table 2 and Proposition 3iii. The second part of Proposition 8iii follows from combining Case 6 of Table 1 with Case 4 of Table 2 and Proposition 3iii.

Proof of the claim: $n>\left[\frac{\left(\sum_{j} w_{j}\right)^{\beta c}}{\sum_{j} w_{j}^{\beta c}}\right]^{\frac{1}{1+\beta c}}>0 \Rightarrow \tilde{w}>w_{\varnothing}$.

We rearrange the inequality $\tilde{w}-w_{\varnothing} \gtreqless 0$ and obtain

$$
\begin{aligned}
& \tilde{w}-w_{\varnothing} \gtreqless 0 \Leftrightarrow\left(\sum_{j} \frac{w_{j}^{-\beta c}}{n}\right)^{-\frac{1}{\beta c}} \gtreqless \frac{\sum_{j} w_{j}}{n} \Leftrightarrow \sum_{j} \frac{w_{j}^{-\beta c}}{n} \lesseqgtr\left(\frac{\sum_{j} w_{j}}{n}\right)^{-\beta c} \Leftrightarrow \\
& \frac{\left(\sum_{j} w_{j}\right)^{\beta c}}{\sum_{j} w_{j}^{\beta c}} \lesseqgtr n^{1+\beta c} \Leftrightarrow\left[\frac{\left(\sum_{j} w_{j}\right)^{\beta c}}{\sum_{j} w_{j}^{\beta c}}\right]^{\frac{1}{1+\beta c}} \lesseqgtr n .
\end{aligned}
$$

With $w_{i}>0$ for $i=1, \ldots, n$ the inequality (A18) proofs the claim. 


\section{CESifo Working Paper Series}

for full list see www.cesifo-group.org/wp

(address: Poschingerstr. 5, 81679 Munich, Germany, office@cesifo.de)

2733 Francesco Cinnirella and Joachim Winter, Size Matters! Body Height and Labor Market Discrimination: A Cross-European Analysis, July 2009

2734 Samuel Bowles and Sandra Polanía Reyes, Economic Incentives and Social Preferences: A Preference-based Lucas Critique of Public Policy, July 2009

2735 Gary Burtless, Lessons of the Financial Crisis for the Design of National Pension Systems, July 2009

2736 Helmuth Cremer, Firouz Gahvari and Pierre Pestieau, Fertility, Human Capital Accumulation, and the Pension System, July 2009

2737 Hans Jarle Kind and Frank Stähler, Market Shares in Two-Sided Media Industries, July 2009

2738 Pamela Campa, Alessandra Casarico and Paola Profeta, Gender Culture and Gender Gap in Employment, August 2009

2739 Sebastian Gechert, Supplementary Private Health Insurance in Selected Countries: Lessons for EU Governments?, August 2009

2740 Leif Danziger, Endogenous Monopsony and the Perverse Effect of the Minimum Wage in Small Firms, August 2009

2741 Yan Dong and John Whalley, A Third Benefit of Joint Non-OPEC Carbon Taxes: Transferring OPEC Monopoly Rent, August 2009

2742 Valentina Bosetti, Carlo Carraro and Massimo Tavoni, Climate Change Mitigation Strategies in Fast-Growing Countries: The Benefits of Early Action, August 2009

2743 Christina Felfe, The Willingness to Pay for Job Amenities: Evidence from Mothers' Return to Work, August 2009

2744 Jörg Franke, Christian Kanzow, Wolfgang Leininger and Alexandra Väth, Effort Maximization in Asymmetric N-Person Contest Games, August 2009

2745 Bruno S. Frey and Paolo Pamini, Making World Heritage Truly Global: The Culture Certificate Scheme, August 2009

2746 Frank N. Caliendo, Is Social Security behind the Collapse of Personal Saving?, August 2009

2747 Caterina Liesegang and Marco Runkel, Corporate Income Taxation of Multinationals and Fiscal Equalization, August 2009 
2748 Chrysovalantou Milliou and Apostolis Pavlou, Upstream Horizontal Mergers and Efficiency Gains, August 2009

2749 Rüdiger Pethig and Christian Wittlich, Interaction of Carbon Reduction and Green Energy Promotion in a Small Fossil-Fuel Importing Economy, August 2009

2750 Kai Carstensen, Oliver Hülsewig and Timo Wollmershäuser, Monetary Policy Transmission and House Prices: European Cross-country Evidence, August 2009

2751 Olaf Posch, Explaining Output Volatility: The Case of Taxation, August 2009

2752 Beatrice Scheubel, Daniel Schunk and Joachim Winter, Don't Raise the Retirement Age! An Experiment on Opposition to Pension Reforms and East-West Differences in Germany, August 2009

2753 Daniel G. Arce, Dan Kovenock and Brian Roberson, Suicide Terrorism and the Weakest Link, August 2009

2754 Mario Larch and Wolfgang Lechthaler, Comparative Advantage and Skill-Specific Unemployment, August 2009

2755 Horst Raff and Nicolas Schmitt, Buyer Power in International Markets, August 2009

2756 Seppo Kari, Hanna Karikallio and Jukka Pirttilä, The Impact of Dividend Taxation on Dividends and Investment: New Evidence Based on a Natural Experiment, August 2009

2757 Mirco Tonin and Michael Vlassopoulos, Disentangling the Sources of Pro-social Behavior in the Workplace: A Field Experiment, August 2009

2758 Nicole Grunewald and Inmaculada Martínez-Zarzoso, Driving Factors of Carbon Dioxide Emissions and the Impact from Kyoto Protocol, August 2009

2759 Yu-Fu Chen and Michael Funke, Booms, Recessions and Financial Turmoil: A Fresh Look at Investment Decisions under Cyclical Uncertainty, August 2009

2760 Jan-Egbert Sturm and Jakob de Haan, Does Central Bank Communication really Lead to better Forecasts of Policy Decisions? New Evidence Based on a Taylor Rule Model for the ECB, August 2009

2761 Larry Karp, Sacrifice, Discounting and Climate Policy: Five Questions, August 2009

2762 Marianna Belloc and Samuel Bowles, International Trade, Factor Mobility and the Persistence of Cultural-Institutional Diversity, August 2009

2763 Charles Noussair and Fangfang Tan, Voting on Punishment Systems within a Heterogeneous Group, August 2009

2764 Birgit Bednar-Friedl and Karl Farmer, Internationally Coordinated Emission Permit Policies: An Option for Withdrawers from the Kyoto Protocol?, August 2009 
2765 Pierre M. Picard and David E. Wildasin, Labor Market Pooling, Outsourcing and Labor Contracts, August 2009

2766 Stefan Voigt and Lorenz Blume, The Economic Effects of Federalism and Decentralization - A Cross-Country Assessment, August 2009

2767 David S. Jacks, Christopher M. Meissner and Dennis Novy, Trade Booms, Trade Busts, and Trade Costs, August 2009

2768 Mario Jametti and Thomas von Ungern-Sternberg, Hurricane Insurance in Florida, August 2009

2769 Alessandro Balestrino, Kind of Black: The Musicians’ Labour Market in Italy, August 2009

2770 Yosr Abid Fourati and Cathal O’Donoghue, Eliciting Individual Preferences for Pension Reform, August 2009

2771 Christian Breuer and Chang Woon Nam, VAT on Intra-Community Trade and Bilateral Micro Revenue Clearing in the EU, August 2009

2772 Choudhry Tanveer Shehzad, Jakob De Haan and Bert Scholtens, Growth and Earnings Persistence in Banking Firms: A Dynamic Panel Investigation, August 2009

2773 Erdal Yalcin, Uncertain Productivity Growth and the Choice between FDI and Export, August 2009

2774 Klaus Abberger, Wolfgang Nierhaus and Shynar Shaikh, Findings of the Signal Approach for Financial Monitoring in Kazakhstan, September 2009

2775 Sascha O. Becker, Francesco Cinnirella and Ludger Woessmann, The Trade-off between Fertility and Education: Evidence from before the Demographic Transition, September 2009

2776 Thomas Aronsson and Erkki Koskela, Optimal Income Taxation, Outsourcing and Policy Cooperation in a Dynamic Economy, September 2009

2777 Joel Slemrod, Old George Orwell Got it Backward: Some Thoughts on Behavioral Tax Economics, September 2009

2778 Cagri Seda Kumru and Athanasios C. Thanopoulos, Social Security Reform and Temptation, September 2009

2779 Alessandro Bucciol and Roel M. W. J. Beetsma, Inter- and Intra-generational Consequences of Pension Buffer Policy under Demographic, Financial and Economic Shocks, September 2009

2780 Eduardo Strube and Marcelo Resende, Complementarity of Innovation Policies in the Brazilian Industry: An Econometric Study, September 2009 
2781 Henry Tulkens and Vincent van Steenberghe, "Mitigation, Adaptation, Suffering": In Search of the Right Mix in the Face of Climate Change, September 2009

2782 Maria L. Loureiro, Anna Sanz-de-Galdeano and Daniela Vuri, Smoking Habits: Like Father, Like Son, Like Mother, Like Daughter, September 2009

2783 Momi Dahan, Tehila Kogut and Moshe Shalem, Do Economic Policymakers Practice what they Preach? The Case of Pension Decisions, September 2009

2784 Eytan Sheshinski, Uncertain Longevity and Investment in Education, September 2009

2785 Nannette Lindenberg and Frank Westermann, How Strong is the Case for Dollarization in Costa Rica? A Note on the Business Cycle Comovements with the United States, September 2009

2786 Leif Danziger, Noncompliance and the Effects of the Minimum Wage on Hours and Welfare in Competitive Labor Markets, September 2009

2787 Gerlinde Fellner, Rupert Sausgruber and Christian Traxler, Testing Enforcement Strategies in the Field: Legal Threat, Moral Appeal and Social Information, September 2009

2788 Gabriel J. Felbermayr, Mario Larch and Wolfgang Lechthaler, Unemployment in an Interdependent World, September 2009

2789 Sebastian G. Kessing, Federalism and Accountability with Distorted Election Choices, September 2009

2790 Daniel Gros, Global Welfare Implications of Carbon Border Taxes, September 2009

2791 Louis N. Christofides, Michael Hoy and Ling Yang, The Gender Imbalance in Participation in Canadian Universities (1977-2005), September 2009

2792 Jan K. Brueckner and Robert W. Helsley, Sprawl and Blight, September 2009

2793 Vidar Christiansen and Stephen Smith, Externality-correcting Taxes and Regulation, September 2009

2794 John Beirne, Guglielmo Maria Caporale, Marianne Schulze-Ghattas and Nicola Spagnolo, Global and Regional Spillovers in Emerging Stock Markets: A Multivariate GARCH-in-mean Analysis, September 2009

2795 Rüdiger Pethig and Frieder Kolleß, Asymmetric Capital-Tax Competition, Unemployment and Losses from Capital Market Integration, September 2009 